UNIVERSIDADE DE SÃO PAULO

FACULDADE DE ZOOTECNIA E ENGENHARIA DE ALIMENTOS

\author{
UNIVERSIDADE DE SÃO PAULO
}

FACULDADE DE ZOOTECNIA E ENGENHARIA DE ALIMENTOS

ANDRESSA VALIM PARCA

RASTREIO CELULAR DE CÉLULAS-TRONCO AMNIÓTICAS CANINAS 


\title{
RASTREIO CELULAR DE CÉLULAS-TRONCO AMNIÓTICAS CANINAS
}

\section{Versão Corrigida}

\author{
Dissertação apresentada à Faculdade de \\ Zootecnia e Engenharia de Alimentos da \\ Universidade de São Paulo, como parte dos \\ requisitos para a obtenção do título de Mestre \\ em Ciências do programa de Pós-graduação em \\ Biociência Animal \\ Área de Concentração: Terapia Celular
}

Orientadora: Prof ${ }^{\mathrm{a}}$. Dra . Daniele do Santos Martins Co- Orientadora: Prof ${ }^{a}$. Dra . Fabiana Fernandes Bressan 


\section{Ficha catalográfica}

Ficha catalográfica elaborada pelo

Serviço de Biblioteca e Informação, FZEA/USP, com os dados fornecidos pelo(a) autor(a)

Valim Parca, Andressa

RASTREIO CBLULAR DE CB́LULAS-TRONCO AMNIÓTICAS

CANINAS / Andressa Valim Parca ; orientadora

DANIBLE DOS SANTOS MARTINS ; coorientadora FABIANA

FERINANDES BRESSAN. -- Pirassununga, 2021.

$41 \mathrm{f}$.

Dissertaçăo (Mestrado - programa de pós-Graduação em Blociencla Animal) -- Faculdade de 2ootecnia e Engenharia de Alimentos, Universidade de săo Paulo.

1. TERAPIA CBLULAR. 2. CÉLULAS TRONCO. 3. RASTREIO. 4. BIOLOGIA. 5. EISIOLOGIA. I. DOS SANTOS MARTINS, DANIBLE, orient. II. FERNANDES BRESSAN, FABIANA, coorient. III. Titulo. 
ANDRESSA VALIM PARCA

\section{RASTREIO CELULAR DE CÉLULAS-TRONCO AMNIÓTICAS CANINAS}

PARCA, A. V. Rastreio celular de células-tronco amnióticas caninas. 2021. 61 f. Dissertação (Mestrado) - Faculdade de Zootecnia e Engenharia de Alimentos, Universidade de São Paulo, Pirassununga, 2021.

Aprovado em:18/ 02/ 2022

Banca Examinadora

Prof. Dra. Daniele dos Santos Martins

Instituição: FZEA/USP

Profa. Dra. Dayane Alcantara

Instituição: UNIFEOB

Prof. Dra. Naira Caroline Godoy

Instituição: FZEA/USP 
Aos meus pais Delvo Antonio Parca Sídnéia Fontes Vatim Parca

À minha avó Ana Salmasso Parca

Aos mens fithos Marcos Eduardo da Sitva Victor Nunes de Magalhães Davú Parca de Magalhães 


\section{Agradecimentos}

Primeiramente agradeço à Deus, pelos enfrentamentos e lutas diárias, hoje resultado de tanta força.

Agradeço à Prof. Dra. Daniele Martins, por aceitar o desafio e me acolher, como sou grata por todo ensinamento, objetividade, franqueza e clareza. Sempre me instigou a ter asas, e hoje concluindo este processo, vejo que não deveria ter dado voz ao medo, e sim seguido seus voos.

Agradeço à Prof. Dra. Fabiana Bressan, por quantos ensinamentos, quantos finais de semana, feriados e noites, executando e alterando protocolos. Seu olhar de pesquisadora tanto me traz referência.

Agradeço Prof. Dr. Carlos Eduardo Ambrósio, por aceitar conversar e dar uma oportunidade à conversa com a Dra. Daniele.

Arina, agradeço imensamente os empréstimos e as risadas fartas, meus dias ao seu lado foram leves.

Naira, obrigada por dispor do seu tempo no final do mestrado. Foi enriquecedor. Suas pontuações me trouxeram clareza sobre o processo vivenciado.

Obrigada Laís e Aline, pelas dúvidas sanadas, ajuda com as fotos, manuseio do EVOS, processo tão importante para minha pesquisa.

Obrigada Paulinho, pelos puxões de orelha com o n amostral, e mesmo em sua correria, me ajudar com a estatística desta pesquisa.

Vanessa Pontes, obrigada por ser o ponto de luz, e minha guia para concretizar esse sonho. Sua clareza, seu despojamento com leveza me ajudaram a estar onde estou hoje.

Obrigada equipe de pesquisa do GDTI, Lu, Lina, Pri, Clesio, Mel, Rodrigo, Mateus, Karen, Tiago e demais; e equipe do LIFE Camila Alampe e meninas da ICs, estar com vocês esses anos compartilhando conhecimentos e experiências.

Por último, mas nunca importante neste processo, agradeço a Deus a família que tenho, em especial meu companheiro de vida, Fernando, quantos choros que ele não via sentido, quantas noites de insônia presenciou, quantas dúvidas explanações, quantos medos relatava. Obrigada por respeitar, por me ouvir, pois, compreender possui suas complexidades, mas o que foi necessário 
agora foi respeito.

Obrigada a todos que direta e indiretamente contribuíram para este projeto seguir, sem vocês, sem a atenção e carinho de cada um, hoje não estaria defendendo esta grande etapa de minha vida. 
"Persistência é o caminho ao êxito"

Charles Chaplin 


\section{RESUMO}

PARCA, A. V. Rastreio celular de células-tronco amnióticas caninas 2021. $61 \mathrm{f}$. Dissertação (mestrado) - Faculdade de Zootecnia e Engenharia de Alimentos, Universidade de São Paulo, Pirassununga, 2021.

O maior objetivo da medicina regenerativa é promover a regeneração dos tecidos lesionados utilizando células-tronco. As células-tronco mesenquimais amnióticas (CTMA) têm sido utilizadas em vários estudos, principalmente devido à facilidade de isolamento do tecido amniótico após o nascimento, às suas propriedades imunomoduladoras e angiogênicas, e também devido ao baixo nível de rejeição. Estas células partilham características tanto de células-tronco embrionárias/fetais como adultas, e em especial, são vantajosas, pois não desencadeiam a ação tumorigênica quando injetadas em animais imunocomprometidos. A utilização em larga escala destas células para terapias seria grandemente beneficiada através de estudos que validem a possibilidade de rastreio em futuras terapias. Neste caso, o nosso objetivo consistiu em avaliar as células estaminais amnióticas caninas (CTMAc) em relação à positividade da fluorescência, longevidade e intensidade. Para tal, as CTMAc do Banco de células GDTI/USP foram submetidos a três condições de marcação: dois fluoróforos comerciais (CellTrace CFSE Cell Proliferation kit - CTrace, e CellTracker Green CMFDA - CTracker) e a expressão da proteína fluorescente verde (eGFP) após transdução lentiviral, visando eleger um rastreador mais adequado para ser utilizado em estudos em animais domésticos, o qual apresente persistência adequada nas células, fácil manuseio e análise. Nossos resultados demonstram que todos os grupos apresentam positividade de fluorescência, contudo em padrões diferentes. Especificamente, o CTrace e o CTracker mostraram fluorescência às 4 horas após a inserção, enquanto a visualização do eGFP ocorreu cerca 48 horas após a transdução. A análise por citometria de fluxo mostrou que os grupos CTrace e CTracker apresentaram valores percentuais superiores a $70 \%$ de células em D7, enquanto em D20, observou-se a manutenção da porcentagem de fluor6encia destes grupos, nas nossas condições, e a diminuição da fluorescência do grupo eGFP. Nosso estudo demonstrou que os fluoróforos comerciais apresentaram agilidade no início da detecção da fluorescência em cerca de 4 horas e apresentaram uniformidade entre repetições, enquanto o grupo eGFP apresentou maior variação entre repetições e 
menor porcentagem de fluorescência, sugerindo portanto uma direção promissora para avaliar o caminho das CTMAc no papel da medicina regenerativa sem integração genômica.

Palavras-chave: Cão. Células-tronco. Rastreamento celular. GFP. 


\section{ABSTRACT}

PARCA, A. V. Cell Screening in Canine Amniotic Stem Cells. 2021. 61f. Thesis (master's degree) - Faculty of Animal Science and Food Engineering, University of São Paulo, Pirassununga, 2021.

The major goal of regenerative medicine is to promote regeneration of injured tissues using stem cells. Amniotic mesenchymal stem cells (AMSCs) have been used in several studies, mainly due to their ease of isolation from amniotic tissue after birth, their immunomodulatory and angiogenic properties, and also due to their low level of rejection. These cells share characteristics of both embryonic/fetal and adult stem cells, and in particular are advantageous in that they do not trigger tumorigenic action when injected into immunocompromised animals. The large-scale use of these cells for therapies would greatly benefit from studies that validate the possibility of screening in future therapies. Here, we aimed to evaluate canine amniotic stem cells (CTMAc) with respect to fluorescence positivity, longevity and intensity. To this end, cTMSCs from the GDTI/USP cell bank were submitted to three labeling conditions: two commercial fluorophores (CellTrace CFSE Cell Proliferation kit- CTrace, and CellTracker Green CMFDA - Ctracker) and the expression of green fluorescent protein (eGFP) after lentiviral transduction, aiming to elect a more adequate tracer to be used in studies in domestic animals, which presents adequate persistence in the cells, easy handling and analysis. Our results demonstrate that all groups show fluorescence positivity, however in different patterns. The analysis by flow cytometry showed that the CTrace and CTracker groups presented percentage values above $70 \%$ of cells in D7, while in D20, it was observed the maintenance of the percentage of fluorescence of these groups, in our conditions, and a decrease in fluorescence from the eGFP group. Our study showed that commercial fluorophores showed agility in the onset of fluorescence detection in about 4 hours and showed uniformity between repeatitions, while the eGFP group maintained fluorescence, however presenting a higher variation and diminished fluorescence percentage, and hence, suggesting a promising direction to evaluate the path of CTMAc in the role of regenerative medicine without genomic integration.

KEY WORDS: Dog. Stem Cells. Cell Tracking. GFP. 


\section{LISTA DE ILUSTRAÇÕES/ FIGURAS}

Figura 1: Rastreio celular in vitro

Figura 2: Aparência Celular da

CTMAc.

Figura 3: Demonstração de células com dificuldade em ter formato fibroblastóide.

Figura 4: Fluorescência das CTMAc nas primeiras 4 horas após inserção dos rastreadores eGFP, CellTrace CFSE Cell Proliferation e CellTracker ${ }^{\mathrm{TM}}$ Green CMFDA.

Figura 5: Comparativo dos Rastreadores celulares das CTMAc eGFP, CellTrace CFSE Cell Proliferation e CellTracker ${ }^{\mathrm{TM}}$ Green CMFDA nas 24 horas e 7 dias (D7) após inserção dos

rastreadores

Figura 6: Evolução da fluorescência dos rastreadores nas CTMAc com eGFP, CTracer e CTracker no dia 16 (D16), dia 22 (D22) e dia 32 (D32)

Figura 7: Comparativos em graficos dos rastreadores CTrace, CTracker e eGFP avaliação

Image J.

Figura 8: Comparativos dos rastreadores CTrace, CTracker e eGFP na citometria de fluxo.

Figura 9: Comparativos em gráficos dos rastreadores CTrace, CTracker e eGFP na citometria de fluxo

Tabela 1: Comparativo e desvio padrão dos com rastreadores eGFP, CellTrace CFSE Cell Proliferation e CellTracker ${ }^{\mathrm{TM}}$ Green

CMFD 


\section{Glossário e Siglas}

ABNT Associação Brasileira de Normas Técnicas

BR Informante brasileiro

CAPES Coordenação de Aperfeiçoamento de Pessoal de Nível Superior

CD34 do inglês: Cluster of Differentiation 34

CD45 Cluster de diferenciação (do inglês, Cluster of Differentiation 45)

CEUA Comitê de Ética no Uso de Animais

CO2 Dióxido de Carbono

COBEA Código Brasileiro de Experimentação em Animais

CTM Células-tronco Mesenquimais

D6 Massa com 6\% de diopsídio

DA Despesas Administrativas

DE Diagnóstico de Enfermagem

DMEM Dulbecco's Modified Eagle's Medium

DMSO Dimetilsulfóxido

DNA Ácido desoxirribonucleico

DOI Destacamentos de Operações de Informações

EGF Fator de Crescimento Epidérmico

ESC Células-tronco embrionárias

EUA United States of America

FL Fluorescência

MHC Complexo Principal de Histocompatibilidade

MO Medula Óssea

MTT Ensaio de captação do corante Tetrazoliun (atividade metabólica mitocondrial) 
PBS

SAS

SFB

SIGMA

Stem Cells

TPP

UV

VEGF
Solução tamponada fosfato-salina

Statistical Analysis System

Soro Fetal Bovino

Sistema de Gerenciamento Militar de Armas

do inglês: Células-tronco

Tireoidite pós-parto

Ultravioleta

Fator de Crescimento do Endotélio Vascular, do inglês vascular 


\section{SUMÁRIO}

1 INTRODUÇÃO E JUSTIFICATIVA

2 REVISÃO DE LITERATURA

2.1 Membrana Amniótica 4

2.2 Célula-Tronco Mesenquimal $\quad 5$

2.3 Célula-tronco Mesenquimal Amniótica Canina 6

2.4 Células-tronco da membrana amniótica e sua aplicabilidade 9

$\begin{array}{lr}2.5 \text { Aplicações de Células-tronco } & 9\end{array}$

$\begin{array}{ll}3.1 \text { eGFP } & 12\end{array}$

$\begin{array}{ll}\text { 3.2 CellTrace CFSE Cell Proliferation kit } & 14\end{array}$

$\begin{array}{ll}\text { 3.3 CellTracker }{ }^{\mathrm{TM}} \text { Green CMFDA } & 15\end{array}$

5 MATERIAIS e MÉTODO 17

$\begin{array}{ll}5.1 \text { Laboratórios } & 17\end{array}$

$\begin{array}{ll}5.2 \text { Obtenção Células-tronco Amnióticas } & 17\end{array}$

$\begin{array}{ll}\text { 5.2.1 Utilização das CTMAc } & 17\end{array}$

$\begin{array}{lc}\text { 5.3 Protocolo de Rastreio Celular } & 18\end{array}$

$\begin{array}{lc}\text { 5.3.1 Transdução lentiviral eGFP em células CTMAc } & 18\end{array}$

$\begin{array}{ll}\text { 5.3.2 CellTrace CFSE Cell Proliferation } & 19\end{array}$

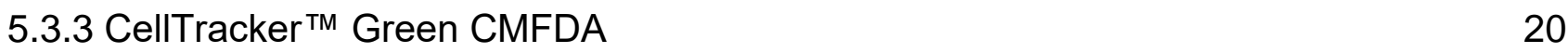

$\begin{array}{ll}5.4 \text { Avaliação in vitro fluorescência } & 20\end{array}$

5.5 Citometria de Fluxo (CF) 21 
6 ANÁLISE ESTATÍSTICA 22

7 RESULTADOS

$\begin{array}{ll}\text { 7.1 Descongelamento das CTM } & 23\end{array}$

$\begin{array}{ll}\text { 7.3 Citometria de Fluxo } & 30\end{array}$

8 DISCUSSÃO

9 CONCLUSÃO

REFERÊNCIAS BIBLIOGRÁFICAS 39 


\section{INTRODUÇÃO E JUSTIFICATIVA}

A ciência visa o uso das células-tronco adultas devido à possibilidade de reparo celular durante o uso em terapias e tratamentos inovadores. Como fonte de célulastronco mesenquimais podemos usar anexos fetais como a membrana amniótica, líquido amniótico e placenta (STEIGMAN et al., 2009), devido a sua característica de capacidade de diferenciação e autorrenovação (DOMINICl et al., 2006).

As células-tronco são células indiferenciadas capazes de realizar a autorrenovação e se diferenciar em sub linhagens mesenquimais, consideradas fontes promissoras para uso em engenharia de tecidos e regeneração de órgãos. As membranas fetais são essenciais para o desenvolvimento embrionário, pois proporcionam a troca materno-fetal, composta por quatro membranas: âmnio, córion, saco vitelino e saco alantóide. O âmnio é a camada mais interna das membranas fetais, e contém uma membrana basal espessa e um estroma avascular, atuando como barreira materno fetal adicional, sua membrana extraembrionária mais interna é composta por uma película, elástica, translúcida e semipermeável, derivada do ectoderma que recobre o feto e está intimamente ligada à membrana coriônica (AMBROSIO et al., 2014).

A segmentação e o rastreamento automatizados de células permitem a quantificação das características estáticas e dinâmicas das células e são importantes para o diagnóstico de doenças, tratamento, desenvolvimento de medicamentos e outras aplicações biomédicas. Estudos de mecanismos de doenças são valiosos para áreas de pesquisa clínica, como pesquisa de células-tronco, engenharia de tecidos, descoberta de medicamentos, genômica e proteômica. As mudanças morfológicas se correlacionam com a progressão da doença (BOUKARI, 2020). Os corantes de rastreamento de células disponíveis comercialmente em suas propriedades químicas e fluorescência, são corantes altamente lipofílicos que se dividem de forma estável, mas não covalentemente em membranas celulares, corantes amino-reativos que formam ligações covalentes estáveis com proteínas celulares (QUAH; WARREN; PARISH, 2007).

As células-tronco derivadas de membrana amniótica apresentam maior capacidade proliferativa e apresentam alta plasticidade e tendência pluripotência 
quando comparadas com as células-tronco mesenquimais. Devido aos seus efeitos imunomodulador, anti-inflamatório e regenerativo espera-se que a terapia celular consiga promover a modulação da resposta inflamatória e consequentemente da cicatrização promovendo melhora funcional (AMBROSIO, 2014).

O uso de modelo canino para estudos ocorre devido à similaridade genética e fisiológica com a espécie humana quando comparada aos modelos dos outros animais experimentais usuais, como camundongos e ratos (KIRKNESS et al., 2003; PARKER; OSTRANDER, 2005). Estudos demonstram que 481 doenças hereditárias foram identificadas em cães domésticos, sendo que mais da metade apresentam-se similares aos humanos como câncer de próstata, câncer de mama, Alzheimer e doenças cardiovasculares (CHASTANT- MAILLARD et al., 2010; RIVERA; EULER, 2011).

Nosso grupo de pesquisa está inserido no cenário mundial da terapia celular através de estudos que abordam temas como tratamento da lesão medular (FEITOSA, 2011; BOCABELLO, 2013; FEITOSA, 2017), caracterização e utilização de célulastronco derivadas de membrana amniótica (VIDANI et al., 2014, 2017; CARDOSO, 2015, 2017; PINHEIRO, 2016; GOMES, 2017), imunomodulação de CT amnióticas caninas (PINHEIRO, 2020) e estudos com CT embrionárias germinativas (PIERI et al., 2019); porém nenhum dos estudos do nosso grupo analisou o caminho percorrido por essas células. Sendo assim, nossa proposta analisará o rastreio celular de forma comparativa utilizando os fluoróforos comerciais (CellTrace CFSE Cell Proliferation kit - CTrace, e CellTracker Green CMFDA - Ctracker) e a expressão da proteína fluorescente verde (eGFP) em células-tronco mesenquimais amnióticas caninas representando uma grande inovação na área, podendo ser repercutida e estendida em outras espécies. 


\section{OBJETIVOS}

- Objetivo Geral

Comparar a intensidade da fluorescência do eGFP comparado aos marcadores CellTrace CFSE Cell Proliferation kit e CellTracker ${ }^{\text {TM }}$ Green CMFDA em Células-tronco Mesenquimais Caninas (CTMAC).

- Objetivos Específicos

- Analisar in vitro o comportamento dos rastreadores CellTrace CFSE Cell Proliferation kit, CellTracker ${ }^{\mathrm{TM}}$ Green CMFDA e eGFP nas CTMAc, para identificação da longevidade de fluorescência;

- Quantificar a fluorescência celular apresentada;

- Avaliar a viabilidade das CTMAc após inserção dos rastreios. 


\section{REVISÃO DE LITERATURA}

\subsection{Membrana Amniótica}

As membranas fetais presentes em mamíferos compreendem o córion, 0 âmnio, alantóide e o saco vitelino, e possuem as funções de proteção, oxigenação, nutrição, excreção e produção de hormônios ao feto/ embrião (MOORE et al., 2004).

O âmnio é a membrana extraembrionária mais interna, composta por uma membrana fina, elástica, translúcida e semipermeável, derivada do ectoderma que recobre o feto e está intimamente ligada à túnica coriônica (FERNANDES et al., 2012).

O líquido amniótico permite que o feto cresça e se mova livremente no útero atuando na troca de substâncias químicas corporais mãe-filho. Em humanos, o líquido amniótico começa a aparecer no início da segunda semana de gestação como um pequeno filme de líquido entre as células do epiblasto. Entre 8 e 10 dias após a fertilização, esse líquido se expande gradualmente e separa o epiblasto (ou seja, o futuro embrião) dos amnioblastos (ou seja, o futuro âmnio), formando assim a cavidade amniótica (KOGAN et al., 2018).

A membrana amniótica possui a função de envolver o embrião, preenchida pelo líquido amniótico, de modo a evitar lesões ao feto através do choque mecânico. Em sua composição possui uma camada epitelial, composta por células amnióticas epiteliais, derivada do ectoderma, e de células estromais mesenquimais que são derivadas do mesoderma. Ambas as populações celulares possuem marcadores semelhantes e potencial para se diferenciar in vitro nas principais linhagens mesodérmicas (FAVARON et al., 2015).

Ao longo da gestação, o volume do líquido amniótico muda acentuadamente de $20 \mathrm{ml} \mathrm{na} 7^{\text {a }}$ semana para $600 \mathrm{ml}$ na $25^{\underline{a}}$ semana e $800 \mathrm{ml}$ no nascimento. Durante a primeira metade da gestação, o líquido amniótico resulta do transporte ativo de sódio e cloreto através da membrana amniótica e da pele fetal não queratinizada, com movimento passivo concomitante de água. Na segunda metade da gestação, o líquido amniótico é constituído pela urina fetal, secreções gastrintestinais, secreções respiratórias e substâncias trocadas pelas membranas (KOGAN et al., 2018).

O líquido amniótico é composto principalmente de água e eletrólitos (98-99\%), mas também contém substâncias químicas (por exemplo, glicose, lipídios, proteínas, 
hormônios e enzimas), materiais suspensos (por exemplo, vérnix caseosa, cabelo lanugo e mecônio) e células (KOGAN et al., 2018).

A membrana amniótica (MA) é um tecido avascular (MIGLINO et al., 2006; DUA et al., 2004). Tem a função de envolver o embrião e delimita a cavidade amniótica, preenchida por líquido amniótico para evitar choques mecânicos (KOOB et al., 2014; MAMEDE et al., 2012).

Basicamente, a membrana amniótica é composta por duas categorias de células: uma camada epitelial composta pelas células amnióticas epiteliais que apresentam morfologia cuboidal ou colunar derivada do ectoderma, e o segundo tipo celular composto de células estromais mesenquimais que são derivadas do mesoderma. Ambas as populações possuem marcadores semelhantes e têm potencial para se diferenciar in vitro nas principais linhagens mesodérmicas (DÍAZPRADO et al., 2010).

A membrana amniótica possui características particulares como ação antiinflamatória, antibacteriana, antiviral e imunológica. Também contém vários fatores de crescimento, citocinas e moléculas de sinalização que desempenham papéis importantes no desenvolvimento fetal e na gestação (KOGAN et al., 2018).

\subsection{Célula-Tronco Mesenquimal}

Células-tronco mesenquimais (CTM ou MSC, do inglês mesenchymal stem cells), são caracterizadas como células-tronco multipotentes capazes de realizar diferenciação em linhagens derivadas do tipo mesodérmico (adipogênicas, condrogênicas, miogênicas e osteogênicas), e até em algumas não mesodérmicas, como as neuronais e hepatócitos (DOMINICI et al., 2006; VIDANE et al., 2013), além de apresentar certas características como aderência ao plástico; e apresentam marcadores como CD105, CD73 e CD90, negativas para CD34, CD45, CD79a ou CD19, CD14 e HLA-DR (HORWITZ et al., 2005).

As células-tronco têm capacidade de diferenciação e autorrenovação. O grande interesse pela ciência por essas células ocorre devido aos seus fatores imunomoduladores e de reparo tecidual que possibilitam o uso em terapias e tratamentos inovadores (FAITA et al., 2016).

Vários tecidos adultos são fontes de células-tronco com potencial terapêutico, como tecido adiposo (RADA et al., 2011). Também é encontra-se CTM emmembranas 
fetais, como a membrana amniótica (MA) (PARK et al., 2012), o líquido amniótico (FAUZA, 2004; STEIGMAN et al., 2009), saco vitelino (MANÇANARES et al., 2015) e placenta (STEIGMAN, 2009).

\subsection{Célula-tronco Mesenquimal Amniótica Canina}

A primeira evidência de que o líquido amniótico poderia conter células-tronco pluripotentes foi fornecida quando Prusa et al., (2003) descreveu a presença de uma subpopulação distinta de células do líquido amniótico em proliferação $(0,1-0,5 \%)$ que expressam o marcador de pluripotência Oct4 nos níveis transcricional e proteico. Oct4 (isto é, fator de transcrição de ligação de octâmero 4) é um fator de transcrição nuclear que desempenha um papel crítico na manutenção do potencial de diferenciação ESC e da capacidade de auto-renovação (CANANZI; DE COPPI, 2012).

As células-tronco amnióticas da membrana (CTMA) foram previamente descritas por suas propriedades imunorreguladoras (BOSSOLASCO et al., 2006), seu potencial de diferenciação e auto-renovação (KITA et al., 2010) e proliferação celular vigorosa. Os CTMA são isolados de diferentes espécies como caninos, felinos, equinos, suínos, murinos e humanos. A aplicação de CTMA ocorre principalmente em cães (A. C. ARAGÃO et al., 2012; CARDOSO et al., 2017) e em gatos (VIDANE et al., 2017), embora o murino e o suíno sejam bons modelos de espécie para estudos em humanos.

As células do líquido amniótico derivam tanto de estruturas extra- embrionárias (isto é, placenta e membranas fetais) quanto de tecidos embrionários e fetais (GOSDEN, 1983). Embora as células do líquido amniótico sejam conhecidas por expressar marcadores de todas às três camadas germinativas sua origem exata ainda representa uma questão de discussão; o consenso é que consistem principalmente de células eliminadas na cavidade amniótica do desenvolvimento da pele, aparelho respiratório, trato urinário e gastrointestinal (FAUZA, 2004).

As células do líquido amniótico apresentam uma ampla gama de morfologias e comportamentos, variando com a idade gestacional e o desenvolvimento fetal. Em condições normais, o número de células do líquido amniótico aumenta com o avanço da gestação; se houver doença fetal, as contagens de células do líquido amniótico podem ser drasticamente reduzidas (por exemplo, morte intrauterina e atresia urogenital) ou anormalmente elevadas (por exemplo, anencefalia e espinha bífida) 
(FAUZA, 2004).

Com base em suas características morfológicas e de crescimento, as células aderentes viáveis do líquido amniótico são classificadas em três grupos principais: epitelioide (33,7\%), líquido amniótico $(60,8 \%)$ e tipo fibroblástico $(5,5 \%)$. No caso de anomalias fetais, outras categorias de células podem ser encontrados no líquido amniótico, por exemplo, células neurais na presença de defeitos do tubo neural e células peritoneais no caso de malformações da parede abdominal. A maioria das células presentes no líquido amniótico são diferenciadas terminalmente e têm capacidades proliferativas limitadas (SIEGEL et al., 2007).

$\mathrm{Na}$ década de 1990, no entanto, dois grupos demonstraram a presença de pequenos subconjuntos de células no líquido amniótico com potencial de proliferação e diferenciação. Primeiro, Torricelli et al., (1993) relataram a presença de progenitores hematopoiéticos no líquido amniótico coletado antes da $12^{-}$semana de gestação. Em seguida, Streubel et al., (1996) conseguiram diferenciar as células do líquido amniótico em miócitos, sugerindo a presença no líquido amniótico de precursores não hematopoiéticos. Esses resultados iniciaram um novo interesse no líquido amniótico como uma fonte alternativa de células para aplicações terapêuticas.

Quase todos os tecidos animais podem ser reparados ou regenerados pela ação direta das células-tronco (MEIRELLES; CHAGASTELLES; NARDI, 2006), que apresentam alto potencial de multiplicação e diferenciação (SNIPPERT; CLEVERS, 2011).

Além dos benefícios já relatados na literatura, as CTM possuem a vantagem de serem isoladas a partir de vários órgãos do organismo, como exemplo: medula óssea, tecido adiposo, membrana sinovial, músculos, derme, dente decíduo, cordão umbilical, placenta, fígado, baço e timo (HORWITZ et al., 2005).

Conceitualmente, as CTM são células que exibem capacidade de autorrenovação, realizam divisão celular assimétrica, gerando células indiferenciadas e mantendo sua capacidade de "haste", possuem potencial para diferenciação em outros tipos celulares (DOMINICl et al., 2006).

Além das características de auto renovação e diferenciação as CTMs têm baixa imunogenicidade, efeitos imunomoduladores, eficiente a inibição de crescimento e ativação de processos celulares da imunidade inata e adaptativa, auxiliando em tratamentos de distúrbios anti mediador, de modo a reduzir a inflamação, promovendo a reparação dos tecidos (MARTI; RIZZO, 2011). 
As membranas fetais participam da formação da placenta de forma associada ou isolada, o âmnio, córion, alantoide e saco vitelino às quatro membranas fetais. $O$ âmnio é a membrana extraembrionária mais interna que envolve o feto e delimita a cavidade amniótica repleta do fluido amniótico proporcionando um nicho para o desenvolvimento do conceito e conferindo proteção e resistência ao impacto. Geralmente o âmnio é descartado após o parto, como um lixo biológico, sendo considerada uma fonte alternativa de CTM que possuem a vantagem de estar isentas de barreiras éticas (FAITA et al., 2016; PEREIRA, 2008).

O fluído amniótico possui aspecto claro, líquido aquoso que envolve o feto em crescimento na cavidade amniótica. Isto permite ao feto crescimento espontâneo e movimento no útero gravídico, composto principalmente de água e eletrólitos (98 a 99\%), mas também contém substâncias químicas (por exemplo, glicose, lipídios, proteínas, hormônios e enzimas) (UNDERWOOD; GILBERT; SHERMAN, 2005). Essas células compartilham características das células-tronco embrionárias e adultas, destacando-se que, ao contrário das embrionárias, as mesenquimais não são tumorigênicas quando injetadas em animais imunocomprometidos (DAVYDOVA et al., 2009; POLONI et al., 2011).

A célula, após interação com CTM, assume vias de sinalização que desencadeiam, além da migração, uma resposta celular focada, levando à proliferação ou diferenciação celular. Quanto maior o favorecimento do gradiente alostérico, melhor e mais rápida será a "decisão" da célula-tronco, que está recebendo sinais diferentes para determinadas funções (KEAN et al., 2013).

Devido às propriedades multipotentes, as células da membrana amniótica têm sido investigadas por serem uma fonte atraente para o transplante de tecidos (MAMEDE et al., 2012). A utilização de CTM da espécie da família Canis familiaris, é importante para medicina regenerativa, pois suas características fisiológicas são semelhantes às de seres humanos (HOLSON, 2015). Além da fisiologia, outro fator que também adequa o cão como modelo experimental é devido ao vasto conhecimento de sua biologia e fisiologia. 


\subsection{Células-tronco da membrana amniótica e sua aplicabilidade}

As CTMA são derivados do mesoderma extraembrionário sendo distribuídos aleatoriamente na matriz extracelular do âmnio, rica em fibras de colágeno e lamina. São células multipotentes com características que favorecem seu uso, como baixa imunogenicidade e carcinogenicidade, produção de moléculas reguladoras do sistema imunológico, alta plasticidade e propagação em cultura e presença de alta concentração de lisossomos (CARDOSO et al., 2017; FAITA et al., 2016; FILIOLI URANIO et al., 2011; VIDANE et al., 2013).

A CTMA demonstra ausência de propriedades imunogênicas e produção de substâncias anti-inflamatórias e bactericidas que proporcionam seu uso no tratamento de feridas cutâneas, úlceras cutâneas e distúrbios oftálmicos, como úlceras de córnea (DÍAZ-PRADO et al., 2010).

Além disso, as CTMA são consideradas excelentes fontes de células-tronco para terapias regenerativas do sistema nervoso devido à capacidade de diferenciação neural (FILIOLI URANIO et al., 2011; PARK et al., 2012).

Essas células apresentam vantagens sobre as células-tronco adultas porque preservam características embrionárias, imunossupressoras e pluripotentes, confirmadas pela expressão de marcadores embrionários como OCT-4 e NANOG (A. C. ARAGÃO et al., 2012; FILIOLI URANIO et al., 2011; SAULNIER et al., 2016).

Outra vantagem CTMAc é que eles são fáceis de adquirir, não oferecem danos aos doadores e têm uma resposta imunológica mais baixa, o que as tornam importantes em pesquisas para medicina regenerativa, visto que a inflamação e imunogenicidade são fatores cruciais para o sucesso do transplante (KIM et al., 2012).

As células derivadas de fluido e membrana amniótica possuem marcadores e características pertinentes à CTM, segundo os critérios da International Society of Cell Therapy (CARDOSO et al., 2016).

Nas últimas décadas o estudo com aplicação de células-tronco mesenquimais em processo de cicatrização vem apresentando resultados satisfatórios em feridas crônicas e agudas (BEHEREGARAY et al., 2017).

Estudos demonstram que a administração de CTMs em lesões agudas de roedores melhora a taxa de cicatrização por acelerar a epitelização, o que aumenta a formação de tecido de granulação e a angiogênese (GIANOTTI, 2015). 
No campo veterinário, as CTMs, isoladas da medula óssea ou do tecido adiposo, através de manipulação mínima, têm sido aplicadas no tratamento de tendões, lesões ligamentares e doenças articulares, com relevância clínica significativa em cavalos e cães em condições ortopédicas. As CTMs demonstraram características hábeis, capacidade imunomoduladora de estimular a angiogênese e reduzir cicatrizes resultando em potencial terapêutico na medicina regenerativa (HOCKING, 2012; OTERO-VIÑAS; FALANGA, 2016).

Para avaliar o tráfego dinâmico e o homing de hUC-MSCs (Human umbilical cord mesenchymal stem cells) em resposta a queimaduras graves in vivo foram aplicados por via intravenosa caudal, $5 \times 10^{6} \mathrm{hUC}$-MSC marcadas com eGFP foram transplantadas em ratos com queimaduras graves e a imagem sequencial BLI foi realizada de 1 a 3 semanas após transplante de hUC-MSC. Na semana 1 após o transplante, observou-se que as hUC-MSCs migraram para as queimaduras graves, e essas hUC-MSCs marcadas com eGFP concentraram-se principalmente na borda da ferida e na base da ferida nas semanas 2 e 3 após o transplante de hUC-MSCs (LIU et al., 2014).

Em um modelo de rato de lesão criogênica da vesícula urinária as CTMAc mostram a capacidade de se diferenciar em músculo liso e de evitar a hipertrofia compensatória das células musculares lisas sobreviventes (DE COPPI et al., 2007).

A administração intraventricular de AFMSC (amniotic fluid mesenchymal stem cells) em camundongos com lesões focais de reperfusão por isquemia cerebral reverte significativamente os déficits neurológicos nos animais tratados (REHNI et al., 2007).

Após a identificação do AFMSC (human amniotic fluid mesenchymal stem cells), vários estudos investigaram seu potencial terapêutico em diferentes contextos experimentais. Em um modelo ovino de hérnia diafragmática, o reparo do déficit muscular usando enxertos modificados com células mesenquimais

autólogas, resultou em estruturas funcionais quando comparadas com enxertos acelulares e à base de mioblastos fetais equivalentes (FUCHS et al., 2004; KUNISAKI et al., 2006). A membrana amniótica já foi utilizada em diversas terapias de animais e humanos, através do tratamento de lesões de pele secundárias a queimaduras químicas e síndrome de Stevens Johnson. Tem-se demonstrado características antiadesão, antibacterianas, imunomoduladoras, e de proteção da ferida, além de facilitar a adesão e migração de células epiteliais basais melhorando a restauração do fenótipo epitelial (A. C. ARAGÃO et al., 2012). 


\section{Rastreadores}

Rastreadores de células fluorescentes são ferramentas poderosas que permitem a visualização direta de processos biológicos, como proliferação celular, migração celular e interações célula-célula (TOMURA, 2008; DE CLERCK, 1994). Os marcadores fluorescentes podem ser corantes de pequenas moléculas ou proteínas fluorescentes. Tipos de células específicas podem ser marcados com proteínas fluorescentes codificadas geneticamente (por exemplo, GFP e YFP) (DAY, 2009). controle adicional sobre a marcação pode ser alcançado usando proteínas fluorescentes como GFP (PATTERSON, 2002) fotoativável e Kaede (TOMURA, 2008; ANDO, 2002) e Kikume fotoconvertíveis (TSUTSUI et al., 2005). Essas proteínas fotoconvertíveis são fluorescentes verdes, mas sofrem uma mudança batocrômica no comprimento de onda de emissão após a irradiação com luz ultravioleta capacidade de controlar a emissão da proteína por irradiação de luz permite aplicações avançadas, por exemplo, em estudos cinéticos de migração celular (SHAND et al., 2014).

Apesar da utilidade das proteínas fluorescentes fotoconvertíveis, sua aplicação é limitada pela disponibilidade do organismo transgênico, e estudos comparativos de nocaute do gene aumentam substancialmente a complexidade da configuração experimental. Em comparação com proteínas fluorescentes codificadas geneticamente (NEMET, 2015) corantes de pequenas moléculas se beneficiam de altos rendimentos quânticos, fotoestabilidade e ajuste químico de suas propriedades (SHAND et al., 2014). Por outro lado, eles também devem cumprir vários requisitos, incluindo permeabilidade da membrana, coloração celular uniforme, resposta fluorogênica no direcionamento intracelular, retenção intracelular e baixa citotoxicidade (WALLACE et al.,2008).

Corantes de proliferação de células comerciais, como eFluor670 e CellTrace Violet (CTV), são usados para quantificar divisões celulares e rastrear populações de células em animais vivos (BEGUM, 2013). Suas estruturas químicas contêm grupos funcionais que podem formar ligações irreversíveis com nucleófilos reativos. No entanto, eFluor670 e CTV estão sempre em estado fluorescente. Este recurso pode causar alta fluorescência de fundo e falsos sinais positivos se a molécula se acumular em um local fora do alvo (FLANAGAN, 2018).

Em contraste, outros rastreadores de células como o éster succinimidílico de 
diacetato de carboxifluoresceína (CFDA-SE) reagem com carboxilesterases intracelulares (CEs) para dar um produto de reação fluorescente brilhante (QUAH; WARREN; PARISH, 2007).

Os grupos succinimidil podem se ligar covalentemente a nucleófilos intracelulares; portanto, rastreadores de células como CFDA-SE podem ser retidos dentro das células, mesmo após a divisão celular (POOT; PIERCE, 2001). Embora essa estratégia aumente a seletividade para nucleófilos intracelulares específicos, a reticulação irreversível com a glutationa reduzida pode afetar o equilíbrio redox da célula e afetar sua função (LULEVICH et al., 2009).

A busca por métodos fluorescentes capazes de detectar cada vez menores quantidades de biomoléculas sofreu muitos avanços nos últimos anos (GWINN; VALLYATHAN, 2006). No entanto, foi com o advento da nanotecnologia que as perspectivas para utilização de nanopartículas em diagnósticos de doenças tornarase a principal promessa das pesquisas médicas, principalmente com os estudos que envolvem administração de medicamentos, terapia e investigação genética, marcação molecular e métodos de detecção óptica, desencadeando uma revolução molecular (BORM, 2006).

A nanotecnologia é interdisciplinar e os avanços de vanguarda indicam a possibilidade de reprodução e estruturação natural de grandes moléculas (BAKER; MAUCK, 2007). Esse desenvolvimento permite o melhor entendimento sobre o metabolismo molecular que transforma energia química em movimento sem praticamente nenhuma perda de energia (DU, 2006).

\section{1 eGFP}

A proteína GFP foi descoberta em 1961 pelo Dr. Osamu Shimomura em 2005 e seu gene foi clonado pela primeira vez por Prasher et al. (1992), de uma água viva de nome científico Aequorea victoria. Além de esclarecer a biologia da bioluminescência do organismo, a clonagem do gene da GFP permitiu expandir sua aplicação para inúmeras áreas da pesquisa biológica, já que o mesmo poderia ser usado como um marcador genético para identificar células e organismos vivos. Inicialmente, a proteína GFP foi usada para se observar células vivas por microscopia de fluorescência, o que permitiu monitorar a localização de proteínas de interesse e 
visualizar eventos celulares (MISTELI et al., 1997).

A utilização da GFP tem sido cada vez mais ampla em estudos de biologia celular, biogênese de organelas, divisão celular de vários organismos, como, por exemplo, do Toxoplasma gondii, parasito do grupo dos apicomplexa e tripanossomatídeos (GUBELLS \& STRIEPEN, 2004). Durante muito tempo, o único marcador utilizado para selecionar plasmódios transfectados era a resistência à pirimetamina, devido à integração de plasmídeos que conferem resistência a esse antimalárico no genoma do parasita (WU et al., 1996).

A GFP é composta por 238 aminoácidos (27 kDa), mas apenas 4 aminoácidos produzem diretamente efeitos fluorescentes (SKELTON, 2001). Sua transfecção ocorre com um gene repórter, onde a proteína de fluorescência verde (GFP) pela primeira vez foi identificada por Chalfie et al. (1994), sua derivação advém da medusa bio quimiluminescente Aequorea victoria (água-viva) (ZHANG et al., 2006).

Até agora, a proteína eGFP foi aplicada para vários propósitos como um marcador útil, entre outros, para o monitoramento vital da eficiência da transfecção de células somáticas e seleção de células transgênicas cultivadas in vitro (HYUN et al. 2003), com o auxílio desse marcador transgênico praticamente ideal, o progresso no desenvolvimento de sistemas eficientes de entrega de genes está bastante acelerado.

O uso da GFP demonstra sua aplicabilidade em biotecnologia, como o fluoróforo faz parte da cadeia peptídica, não sendo necessário adicionais para florescer (FARIAS, 2009).

Novas tecnologias baseadas em imagens fluorescentes e luminescentes avançaram rapidamente na última década (OZAWA; YOSHIMURA; KIM, 2013). Os repórteres fluorescentes permitem uma visualização mais clara e exigem tempos de exposição mais curtos que a bioluminescência. Além disso, o uso de proteínas fluorescentes elimina a necessidade de substratos ou cofatores, permitindo a análise em tempo real de sistemas inteiros usando imagens ao vivo (KONG; CIRILLO, 2018; RAMACHANDRAN et al., 2017).

A engenharia genética de diferentes espectros, alterando os comprimentos de onda de excitação e emissão da proteína, aumentou o brilho e superou o ruído de fundo, que foi uma etapa fundamental na otimização do primeiro repórter GFP de Aequorea victoria (água-viva) (PRASHER et al., 1992). Os derivados de GFP foram desenvolvidos para emitir cinco cores principais: ciano, verde, amarelo, laranja e vermelho. No entanto, esses comprimentos de onda da luz são absorvidos pelo tecido 
hospedeiro, portanto, esses repórteres não eram ideais para estudos de tecidos in vivo e profundo (CHUDAKOV; LUKYANOV; LUKYANOV, 2005).

A fluorescência de GFP é explicada pela presença de um cromóforo denominado phidroxibenzilideneimidazolidinona formado pela ciclização e oxidação autocatalítica dos resíduos de três aminoácidos contínuos próximos ao aminoácido terminal da proteína (SerTyr-Gly), nas posições 65-67 (CODY et al., 1993). A formação do cromóforo ocorre independente da adição de cofatores e com a proteína solubilizada, uma vez que em estado insolúvel a cadeia polipeptídica é incapaz de adquirir a conformação ativa da proteína (REID E FLYNN, 1997).

Com a expressão heteróloga de GFP ativa, as perspectivas de utilização dessa proteína como ferramenta para pesquisa in vivo se tornam ilimitadas. As primeiras clonagens foram realizadas em células de Escherichia coli e Caenohabidtis elegans (CHALFIE et al., 1994) e em Drosophila melanogaster (WANG E HAZELRIGG, 1994), demonstrando a capacidade de expressão de GFP tanto em organismos procariotos como em eucariotos. Também foi possível confirmar que a formação do cromóforo não necessita de substrato ou de enzima específica de $A$. victoria, assim como nenhum cofator para induzir a fluorescência.

O dano celular, causado pela transfecção / transdução de GFP pode levar a uma interpretação errônea dos resultados experimentais. O dano celular é descrito como possivelmente resultante de lesão direta pela geração de espécies reativas de oxigênio (ROS), início da apoptose e dano por mecanismos imunológicos (ANSARI, 2016).

Wu e colaboradores (2007), demonstraram que as injeções de CTMs marcadas com proteína verde-fluorescente (GFP + CTM) ao longo da periferia das úlceras conseguiram acelerar a reepitelização, promover a angiogênese e aumentar a expressão de fatores de crescimento vascular e endotelial. Além disso, quando a aplicação de fibroblastos dérmicos alogênicos neonatais foi comparada com o meio de controle do veículo, a expressão da angiopoietina-1 aumentou, tanto em camundongos normais quanto em diabéticos as células mesenquimais curaram com sucesso feridas agudas e crônicas em modelos experimentais e em pacientes. 


\subsection{CellTrace CFSE Cell Proliferation kit}

O corante fluorescente intravital, éster de carboxi fluorescência diacetato succinimidil (CFSE), que possui ação não citotóxica, tem sido utilizado amplamente em estudos para rastreio de migração linfocitária e célula imune. Tradicionalmente usado para caracterizar a proliferação celular in vivo, o éster de carboxifluoresceína succinimidil (CFSE) demonstrou marcação celular estável em cultura (AHRENS et al., 2005).

Os reagentes CellTrace têm grupos acetatos para cobrir as cargas nos corantes para torná-los permanentes celulares e grupos reativos com amina éster de succinimidil para retenção de longo prazo. Tanto os acetatos como os ésteres de succinimidil hidrolisam prontamente se houver água durante 0 armazenamento. 0 sulfóxido de Dimetilo (DMSO) é higroscópico, portanto, absorve rapidamente a água da atmosfera. Se você precisar armazenar seus estoques de corante, você precisará usar um estoque de DMSO anidro de boa qualidade que não tenha sido aberto com frequência e selar os frascos e colocá-los em um local hermético contendo algum dessecante para manter a solução de estoque de DMSO / corante. Sua forma de armazenamento deve ser de -20 graus, com utilização em curto período (LI et al., 1997).

Reagentes de proliferação celular CellTrace são todos corantes permeantes de células clivados por esterases intracelulares para produzir compostos altamente fluorescentes que também se ligam covalentemente a aminas celulares, anexando o corante a vários componentes celulares e fornecendo um sinal muito estável. Esses reagentes mostram pouca citotoxicidade com efeitos mínimos observados na capacidade proliferativa de muitas células (ROSENBLATT, 1997).

As células precisam de 10-20 min de incubação para passar pela desesterificação, e com fornecimento de fluorescência brilhante em toda a célula, se estendendo por 3-6 gerações ou 72 horas (SIMON, 1997).

\subsection{CellTracker ${ }^{\mathrm{TM}}$ Green CMFDA}

$\mathrm{Na}$ geração atual, os marcadores fluorescentes são feitos de pequenas moléculas de corantes, amplamente utilizados, desde a decodificação do DNA ao auxílio no diagnóstico de infecções (MARSH et al., 2007). Os corantes orgânicos, 
entretanto, podem ser tóxicos e sofrer desgaste rápido. Além disso, a geração da luminescência requer o bombeio da molécula em ressonância, o que leva à situação típica em que cada corante é excitado por fótons em comprimentos de ondas diferentes (SZENT-GYORGVI et al., 2008). Os pontos quânticos coloidais ou nanocristais, por outro lado, não são tóxicos e sua fluorescência continua ativa por um tempo 100 vezes maior, comparado aos corantes orgânicos (MARSH et al., 2007).

Em sua explicação fisiológica, o corante fluorescente CellTracker ${ }^{\mathrm{TM}}$ Green CMFDA foi concebido para passar livremente através das membranas celulares para as células, onde é transformado em produtos de reação impermeabilizantes da membrana celular. O CellTracker ${ }^{\mathrm{TM}}$ Green CMFDA é retido em células vivas através de várias gerações. O corante é transferido para células-filhas, mas não células adjacentes da população, não possui toxicidade para as células e fluorescente em pH fisiológico.

Os corantes CellTracker são melhores para rotulagem de longo prazo, visto que possuem uma porção clorometil moderadamente reativa que permite a ligação covalente aos componentes celulares. CFDA também se liga covalentemente a componentes celulares. Com todos os reagentes, sua retenção nas células depende da taxa de divisão celular e das propriedades inerentes da célula (efluxo ativo, taxas de renovação de membrana e proteína) e os reagentes que permitem a ligação covalente exibe retenção mais longa (CHEN, 2019).

As opções mais duradouras e brilhantes são os reagentes Qtracker, absorvidos por endocitose. Esses são pontos quânticos individuais tão brilhantes que podem ser detectados e também são robustos o suficiente para sobreviver não apenas à fixação e permeabilização, mas até mesmo ao calor e aos solventes usados no processamento da parafina (YEHUDAI-RESHEFF, 2018).

Os corantes de rastreamento exibem propriedades ideais, são estáveis, não tóxicos em concentrações de trabalho, bem retidos nas células e fortemente fluorescentes em pH fisiológico. Corantes CellTracker têm uma ampla gama de espectros de emissão para fácil combinação com a coloração de anticorpos (BANGCHRISTENSEN, 2019). 


\section{MATERIAIS E MÉTODO}

O presente estudo seguiu a diretriz da Sociedade Brasileira de Ciência em Animais de Laboratório (SBCAL) sendo aprovado pelo Comitê de Ética em Experimentação Animal (CEUA) da Faculdade de Zootecnia e Engenharia de Alimentos, Universidade de São Paulo (FZEA-USP) sob registro de processo no 4292 300719 , na data 30/07/2019.

\subsection{Laboratórios}

Esta pesquisa foi realizada com a colaboração de três laboratórios, todos pertencentes à Universidade de São Paulo, Faculdade de Zootecnia e Engenharia de Alimentos, Departamento de Medicina Veterinária ZMV/FZEA/USP, sendo eles: laboratório de Imuno-histoquimica e Fisiologia Experimental (LIFE/FZEA/USP), Laboratório de Células-tronco e Terapias Gênicas (GDTI/FZEA/USP) e Laboratório de Morfofisiologia Molecular e Desenvolvimento (LMMD/FZEA/USP).

A inserção e avaliação dos rastreadores CellTrace CFSE Cell Proliferation kit, CellTracker $^{\text {TM }}$ Green CMFDA e eGFP, foram realizados em instalação com Nível de Biossegurança 2 (BL2) (licença número 7342- CTNBio), no LMMD/FZEA/USP.

\subsection{Obtenção Células-tronco Amnióticas}

\section{Banco de Células-tronco Mesenquimais de Âmnio Canina (CTMAc)}

Nesta pesquisa foi utilizadas células de terço médio e final, previamente caracterizadas, em passagem 0 (P0), e passagem 1 (P1) para posterior expansão e utilização em passagem 2 (P2), durante as avaliações em triplicata biologica e técnica.

As células provenientes de membranas aminióticas caninas utilizadas neste trabalho são provenientes do Banco de Células-tronco do Laboratório de Célulastronco e Terapias Gênicas GDTI/FZEA/USP. As células estão caracterizadas e todo o protocolo de coleta e caracterização pode ser encontrado em pesquisas desenvolvidas pelo grupo de Terapias Inovadoras pertencentes ao GDTI/FZEA/USP, nos quais citamos trabalhos de Vidani et al. (2014 e 2017), Cardoso (2015 e 2017), Pinheiro (2016) e Gomes (2017). 


\subsubsection{Utilização das CTMAc}

Para utilização das células, as mesmas foram retiradas do nitrogênio e colocadas cuidadosamente em banho-maria à $38^{\circ} \mathrm{C}$, logo após adicionou-se $1 \mathrm{~mL}$ de meio de cultura DMEM/F12 (Invitrogen, Carlsbad, EUA) suplementado com 15\% de soro bovino fetal, $1 \%$ de aminoácidos não essenciais, $1 \%$ de L-glutamina e 1\% de penicilina/estreptomicina (Sigma) ao tubo criogênico 2,0 ml (KASVI), de forma lenta, como descrito por BERTASSOLI (2012), com a ressuspensão das células e centrifugação por 5 minutos a 1200 rpm, ao final do processo de centrifugação as células sobrenadantes foram descartadas e adicionado novamente meio de cultivo DMEM/F12 (Invitrogen, Carlsbad, EUA) suplementado com 15\% de soro bovino fetal, $1 \%$ de aminoácidos não essenciais, $1 \%$ de L-glutamina e $1 \%$ de penicilina/estreptomicina (Sigma), para dissociação do pellet. As células foram contadas com auxílio da câmara de Neubauer e pipetadas $3 \times 10^{4}$ em placa de 6 poços, com fundo chato, com superfície lisa tratada e borda elevada, fabricado em poliestireno, livre de DNase, RNase, livre de substâncias citotóxicas e esterilizado por radiação gama de cultivo e mantidas na estufa a $38,5^{\circ} \mathrm{C}$ e $5 \% \mathrm{CO}_{2}$.

Para avaliação dos rastreios, utilizamos placas de 6 poços, sendo utilizada 3 poços com $3 \times 10^{4}$ para a realização de triplicata técnica e biológica das soluções LENTIVIRAL FUGW e rastreadores de nanocristais CellTrace e CellTracker ${ }^{\mathrm{TM}}$ Green CMFDA. A troca do meio foi realizada a cada 48 horas desde sua retirada ao nitrogênio. E após 24 horas observado seu estado de aderência à placa e aspecto fibroblastóide, em passagem 2 (P2), no laboratório de morfofisiologia (LMMD/FZEA/USP) as células foram preparadas para colocação dos rastreadores.

\subsection{Protocolo de Rastreio Celular}

\subsubsection{Transdução lentiviral eGFP em células CTMAc}

As CTMAc neste período que antecede a transdução foram cultivadas em meio de cultura com DMEM/F12 (Invitrogen, Carlsbad, EUA) suplementado com 15\% de soro bovino fetal, $1 \%$ de aminoácidos não essenciais, $1 \%$ de L-glutamina e 1\% de penicilina/estreptomicina (Sigma). 
As partículas lentivirais foram produzidas através da lipofecção de células 293FT (Invitrogen) com o reagente Lipofectamina 2000 (Invitrogen). Para tal, $5 \times 10^{6}$ células 293FT foram plaqueadas no dia anterior em placas de cultivo de $100 \mathrm{~mm}$ de modo que apresentassem $90 \%$ de confluência no momento da transfecção (Figura 1). Foram utilizados $12 \mu \mathrm{g}$ dos vetores STEMCCA e $2 \mu \mathrm{g}$ de cada vetor auxiliar, com exceção do plasmídeo VSVG, sendo utilizados $2,4 \mu \mathrm{g}$ (protocolo adaptado de Darrell N. Kotton e Gustavo Mostoslavsky, Center for Regenerative Medicine -ReM, Boston University, comunicação pessoal). A lipofecção foi incubada por 12 a 16 horas (overnight) em contato com as células, quando então o meio foi trocado. $O$ sobrenadante (meio de cultivo) foi recolhido e reposto após 24,48 e 72h após transdução, filtrado e mantido a $4{ }^{\circ} \mathrm{C}$. Até serem concentrados em ultracentrífuga (Beckman Coulter) por $1 \mathrm{~h} 40 \mathrm{~min}$ a $48960 \mathrm{~g}$ no rotor SW28. As partículas virais foram utilizadas no mesmo dia ou congeladas e mantidas a $-80^{\circ} \mathrm{C}$ e utilizadas quando necessários (ZHANG et al., 2006).

Na placa com o vírus FUGW em triplicata técnica as CTMAc foram transduzidos com a incubação overnight com o sobrenadante viral. A expressão de eGFP nas células foi monitorada sob um microscópio UV invertido (EVOS® , Thermo Fisher).

Figura 1 - Rastreio celular in vitro

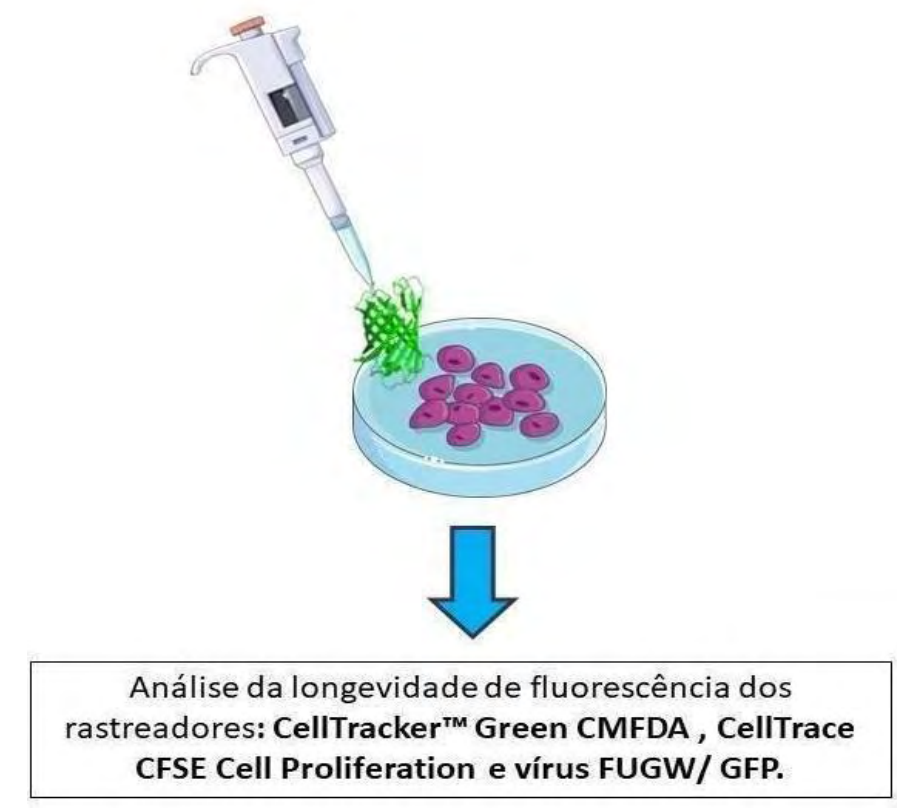

Fonte: PARCA, A.V.

Legenda: Simulação da inserção do rastreio eGFP. 


\subsubsection{CellTrace CFSE Cell Proliferation}

O processo de preparação e alíquota de rastreio do kit CellTrace CFSE ellProliferation, ocorreu conforme preestabelecido pelo fabricante. Para a inserção do nanocristal CellTrace CFSE Cell Proliferation, o meio de cultivo DMEM/F12 (Invitrogen, Carlsbad, EUA) suplementado com 15\% de soro bovino fetal, $1 \%$ de aminoácidos não essenciais, $1 \%$ de L-glutamina e 1\% de penicilina/estreptomicina (Sigma), foi descartado e em seguida as células foram lavadas com $1 \mathrm{ml}$ de tampão fosfato-salino (PBS), e após acrescentamos 2,5ul do CellTrace CFSE Cell Proliferation (Thermo Fisher Scientific) em cada poço; após 20 minutos com ausência de luz, por ser fotossensível, as células foram levadas à estufa a 38,5ํ․ $\mathrm{C}$.

Após o período de incubação, as CTMAc foram lavadas com meio de cultivo DMEM/F12 (Invitrogen, Carlsbad, EUA) suplementado com 15\% de soro bovino fetal, $1 \%$ de aminoácidos não essenciais, $1 \%$ de L-glutamina e $1 \%$ de penicilina/estreptomicina (Sigma), a fim de inativar a CFSE. Após 4 horas, foram realizadas fotos com fluorescência no EVOS® .

\subsubsection{CellTracker ${ }^{\mathrm{TM}}$ Green CMFDA}

Nas placas com rastreadores de nanocristais, realizamos o protocolo preestabelecido pelo fabricante. Para inserção do CellTracker ${ }^{\mathrm{TM}}$ Green CMFDA, retiramos o meio, adicionamos corante, incubamos por 45 minutos e colocamos meio novamente, e ao analisarmos em UV foi possível observar fluorescência.

O corante CellTracker TM Green CMFDA é projetado para exibir fluorescência por pelo menos 72 horas, e o corante exibe propriedades de rastreamento ideais: é estável, não tóxico em concentrações de trabalho, bem retido nas células e fortemente fluorescente em pH fisiológico. Além disso, os espectros de excitação e emissão do corante CellTracker TM Green CMFDA são bem separados dos espectros de RFP (proteína fluorescente vermelha), permitindo a marcação múltipla

\subsection{Avaliação in vitro fluorescência}

As células foram analisadas in vitro, por fotos diárias, com auxílio do microscópio de luz UV EVOS® FL Cell Imaging System, em objetiva 10, fluorescência 
à 20\% (unidade arbitrária) para análise de longevidade e potencial comparação in vivo da ação das CTMAc. Analisamos a fluorescência entre grupos de rastreio, com 3 fotografias de cada quadrante de cada poço ratsreado através do EVOS® CTrace, CTracker e eGFP, as células tiveram o meio trocados a cada 48 horas; o meio de cultivo era composto por DMEM/F12 (Invitrogen, Carlsbad, EUA) suplementado com $15 \%$ de soro bovino fetal, $1 \%$ de aminoácidos não essenciais, $1 \%$ de L-glutamina e $1 \%$ de penicilina/estreptomicina (Sigma), as células foram mantidas em estufa a $38,5^{\circ} \mathrm{C}$.

A densidade integrada modificada de fluorescência verde dos marcadores CTrace, CTracker e eGFP nas imagens adquiridas foi medida usando a imagem $\mathrm{J}$ é expressa como gráficos de barras (Gráfico 7).

\subsection{Citometria de Fluxo (CF)}

Para avaliação de cada rastreio celular CellTrace CFSE Cell Proliferation,

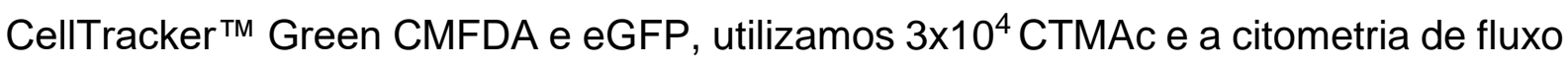
foi realizada após 7 dias de inserção do rastreio (D7) e no vigésimo dia de rastreio (D20). Para a quantificação da densidade de fluoróforo utilizamos o equipamento FACSAria ou Accuri, Beckton Dickinson Ltda e software FACSDiva v.6.2.1.

As células aderidas à placa de 6 poços (KASVI), passaram pelo processo de dissociação com auxílio da TrypLE ${ }^{\mathrm{TM}}$ Express sem Phenol (Thermo Fisher), e após a inaderência celular foi distribuído em tubo cônico tipo Falcon de $15 \mathrm{~mL}$ (Corning Life Science) e centrifugados a $1200 \mathrm{rpm}$ por $5 \mathrm{~min}$. Descartou-se o meio com tripsina priorizando o pellet formado, o qual foi ressuspendido em $500 \mu \mathrm{l}$ de meio de cultivo DMEM/F12 (Invitrogen, Carlsbad, EUA) suplementado com 15\% de soro bovino fetal, $1 \%$ de aminoácidos não essenciais, $1 \%$ de L-glutamina e $1 \%$ de penicilina/estreptomicina (Sigma), e as células foram levadas ao citômetro (FACSAria, Beckton Dickinson Ltda.) usado o software (FACSDiva v.6.2.1) para análise. 


\section{ANÁLISE ESTATÍSTICA}

Os dados obtidos dos procedimentos experimentais foram analisados utilizando o programa estatístico SAS University Edition e realizou-se a verificação da normalidade dos resíduos pelo teste de Shapiro-Wilk. As variáveis que não atenderam às premissas estatísticas foram submetidas à transformação logarítmica [Log $(X+1)]$. Os dados originais ou transformados, quando este procedimento foi necessário, foram submetidos à Análise de Variância e teste de Tukey para comparação entre os diferentes grupos experimentais. À análise estatística foi adicionado o fator medidas repetidas no tempo, referentes aos diversos momentos de amostragem. As análises por tempo somente foram realizadas quando as interações entre tempo e tratamentos foram significativas. Em todas as análises estatísticas, o nível de significância considerado foi de $5 \%$. 


\section{RESULTADOS}

\subsection{Descongelamento das CTM}

Para utilização das CT oriundas do Banco de Células-tronco do Laboratório de Células-tronco e Terapias Gênicas (GDTI/FZEA/USP) as mesmas foram avaliadas como apropriadas para a inserção do rastreio quando descongeladas apresentaram aderência à parede da placa, morfologia fibroblastóide e com cerca de $80 \%$ de confluência (Figura 2).

Figura 2: Aparência Celular da CTMAc

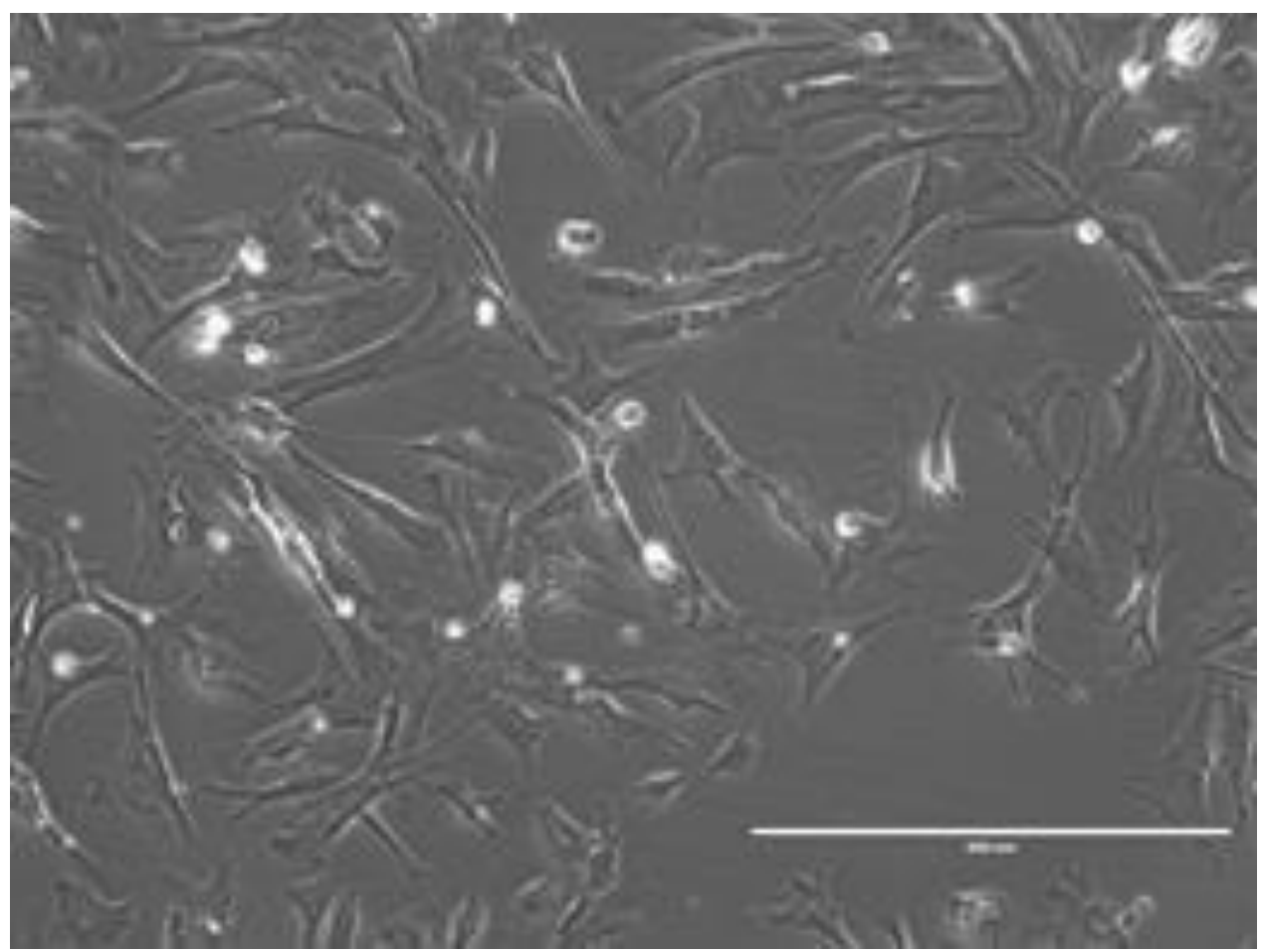

Fonte: PARCA, A.V.

Legenda: Aparência fibroblastóide das CTMAc aderidas à placa. (Microscópio EVOS Cell Imaging Systems|Thermo Fisher Scientific - BR). Barra: $400 \mu \mathrm{m}$. 
Figura 3: Demonstração de células com dificuldade em ter formato fibroblastóide
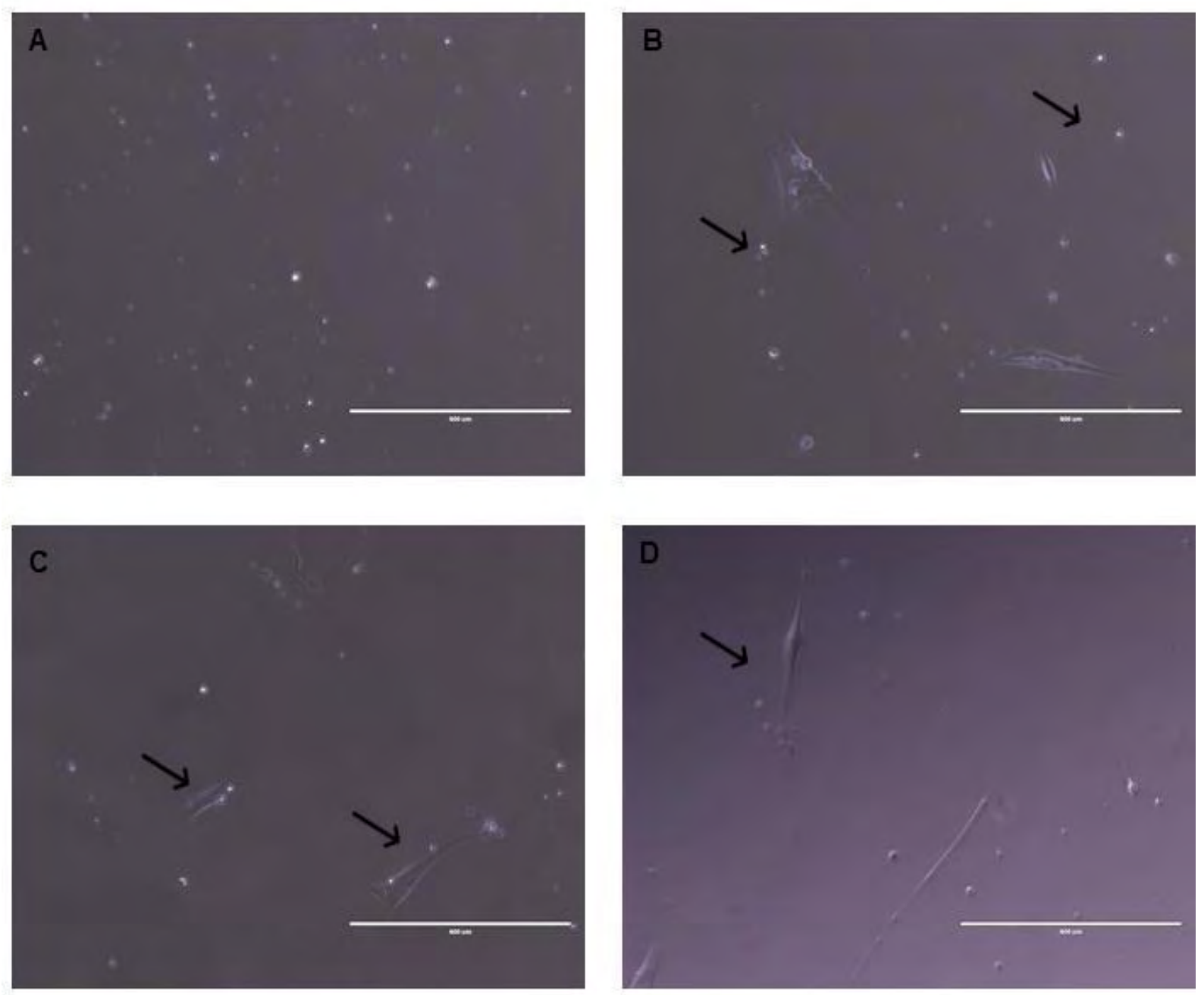

Fonte: PARCA, A.V.

Legenda: Letargia das CTMAc em desenvolver o formato fibroblastóide aderidas à placa. A) Poço inteiro com células apresentando abaulamento B) Misto de CTMAc com início de céulas em formato fibroblastóide e células abauladas. $C$ e D) Células mantendo formato fibroblatóide (Microscópio EVOS Cell Imaging Systems|Thermo Fisher Scientific - BR). Barra: $400 \mu \mathrm{m}$. 
Após seu descongelamento, seguindo protocolo padrão, algumas amostras demonstraram letargia para atingirem confluência e aderência ao plástico nos primeiros 7 dias (Figura 3).

Os resultados encontrados na análise in vitro, demonstraram uma rápida identificação fluorescente dos rastreadores CellTrace CFSE Cell Proliferation kit e CellTracker ${ }^{\mathrm{TM}}$ Green CMFDA, cerca de 4 horas após sua aplicação (Figura 4), enquanto o marcador eGFP demonstrou fluorescência após 48 horas. Neste processo, as células mantiveram a morfologia fibroblastóide mesmo após inserção dos rastreadores CTracker, CTrace e eGFP, pode-se perceber que as células CellTrace (B1), em imagem sem UV, se dissipam, perdendo neste momento a congruência típica das CTM.

Durante a avaliação por fotomicrografia as CTMAc coradas com os rastreadores comerciais CTrace e Ctracker demonstraram fluorescência UV contínua nas 24 horas após inserção, enquanto o rastreador eGFP não demonstrou fluorescência neste mesmo período (Figura 5).

Durante a avaliação comparativa, as células marcadas com CTrace, CTracker e eGFP permanecem marcadas até o $32^{\circ}$ dia de avaliação, sob luz UV, demonstrando morfologicamente formato típico de células-tronco.

O período de queda dos rastreadores comerciais ocorreram após 20 dias, sendo perceptivel à sensibilidade da citometria de fluxo (CF), quando comparada à avaliação da CF no $7^{\circ}$ dia após inserção (Figura 6). 
Figura 4: Fluorescência das CTMAc nas primeiras 4 horas após inserção dos rastreadores eGFP, CellTrace CFSE Cell Proliferation e CellTracker ${ }^{\mathrm{TM}}$ Green CMFDA.

GFP

CellTrace

\section{CellTracker}

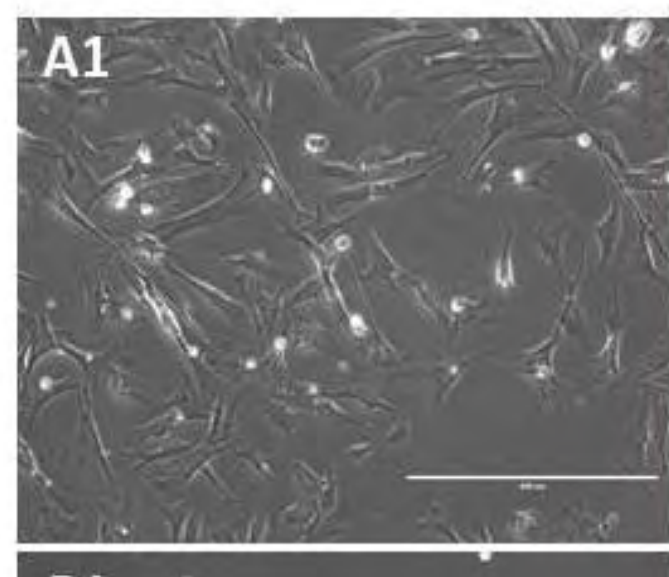

\section{A2}
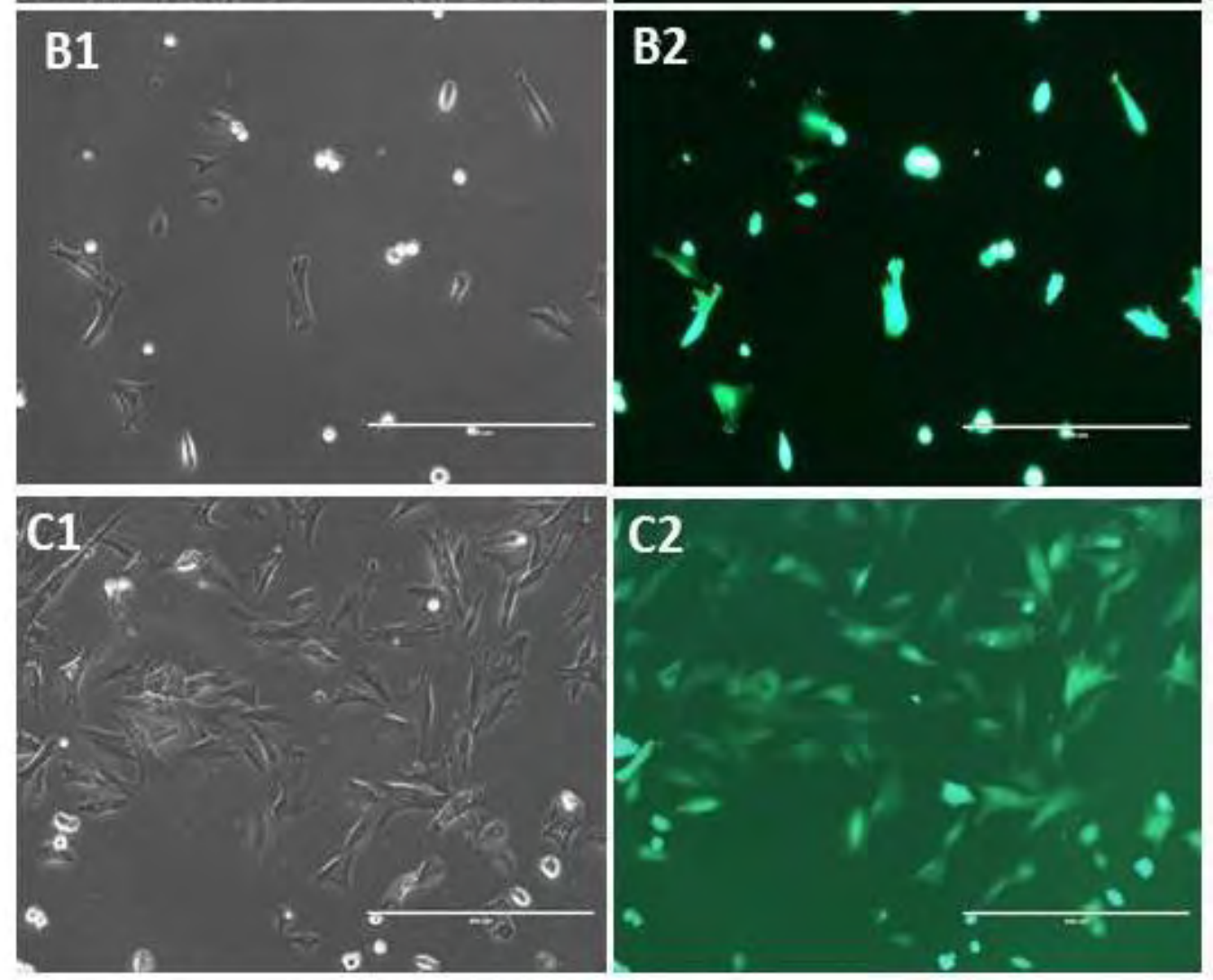

Fonte: PARCA, A.V.

Legenda: Fotomicrografias das CTMAc sem (A1, B1 e C1) e com fluorescência (A2, B2 e C2) nas primeiras 4 horas após inserção. Na figura A2 podemos notar que a marcação por eGFP não fica evidente, enquanto nas figuras B2 e C2 evidenciamos a existência de células fluorescentes indicando a presença dos marcadores CellTrace e CellTracker respectivamente. Microscópio EVOS Cell Imaging Systems|Thermo Fisher Scientific - BR. Barra: $400 \mu \mathrm{m}$. 
Figura 5: Comparativo dos Rastreadores celulares das CTMAc eGFP, CellTrace CFSE Cell Proliferation e CellTracker ${ }^{\mathrm{TM}}$ Green CMFDA nas 24 horas e 7 dias (D7) após inserção dos rastreadores.

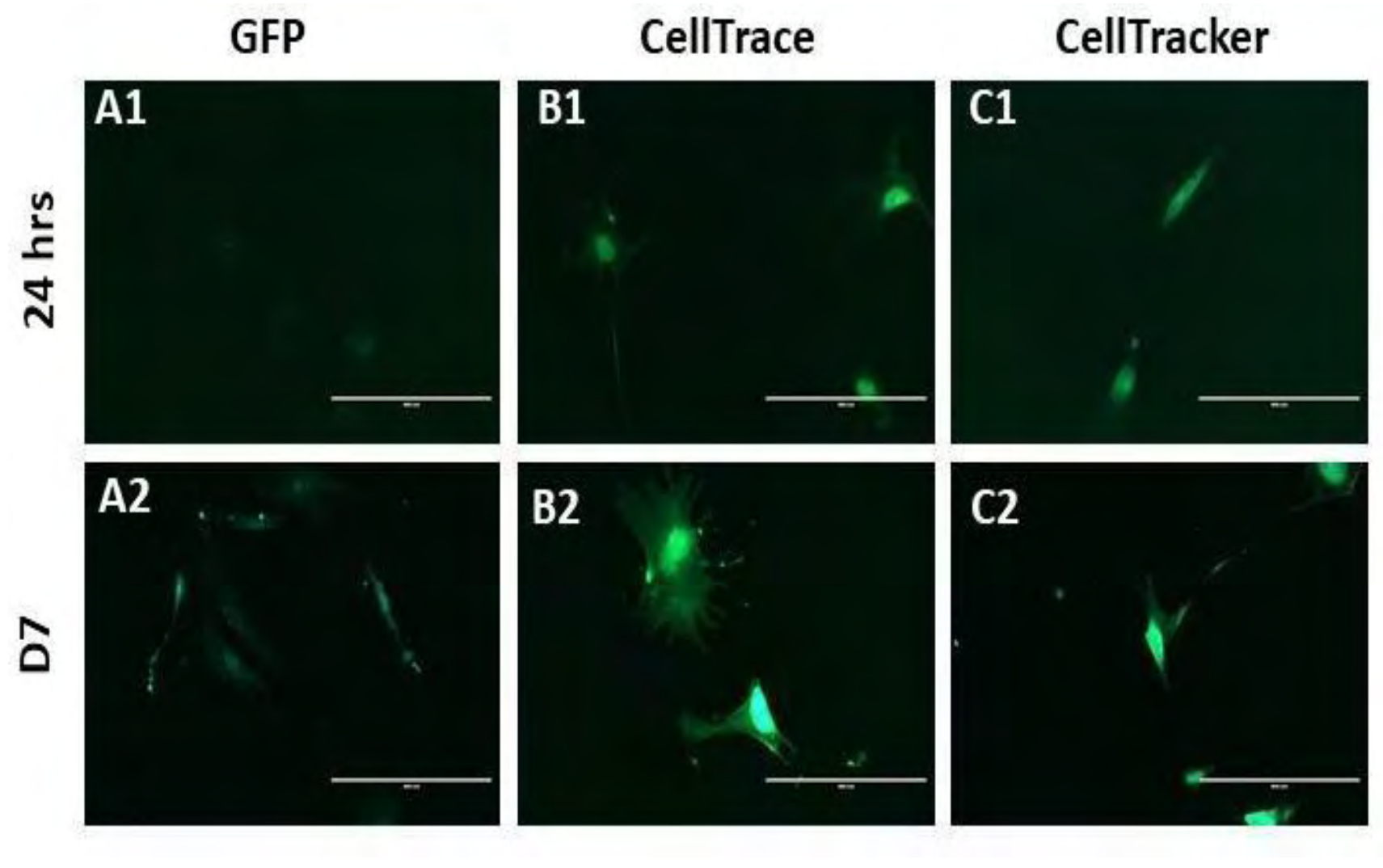

Fonte: PARCA, A.V.

Legenda: Demonstração da fluorescência dos rastreadores eGFP, CellTrace CFSE Cell Proliferation e CellTracker ${ }^{\text {TM }}$ Green CMFDA nas células CTMAc comparativas nas primeiras 24 horas e dia 7 (D7). A1 Podemos destacar que durante as primeiras 24 horas, as CTMAc com eGFP, não demonstraram grande nível de fluorescência, enquanto em B1, C1 a fluorescecia apresenta-se com maior intensidade. Microscópio EVOS Cell Imaging Systems|Thermo Fisher Scientific - BR). Barra: $400 \mu \mathrm{m}$. 
Figura 6- Evolução da fluorescência dos rastreadores nas CTMAc com eGFP, CTrace e CTracker no dia 16 (D16), dia 22 (D22) e dia 32 (D32).
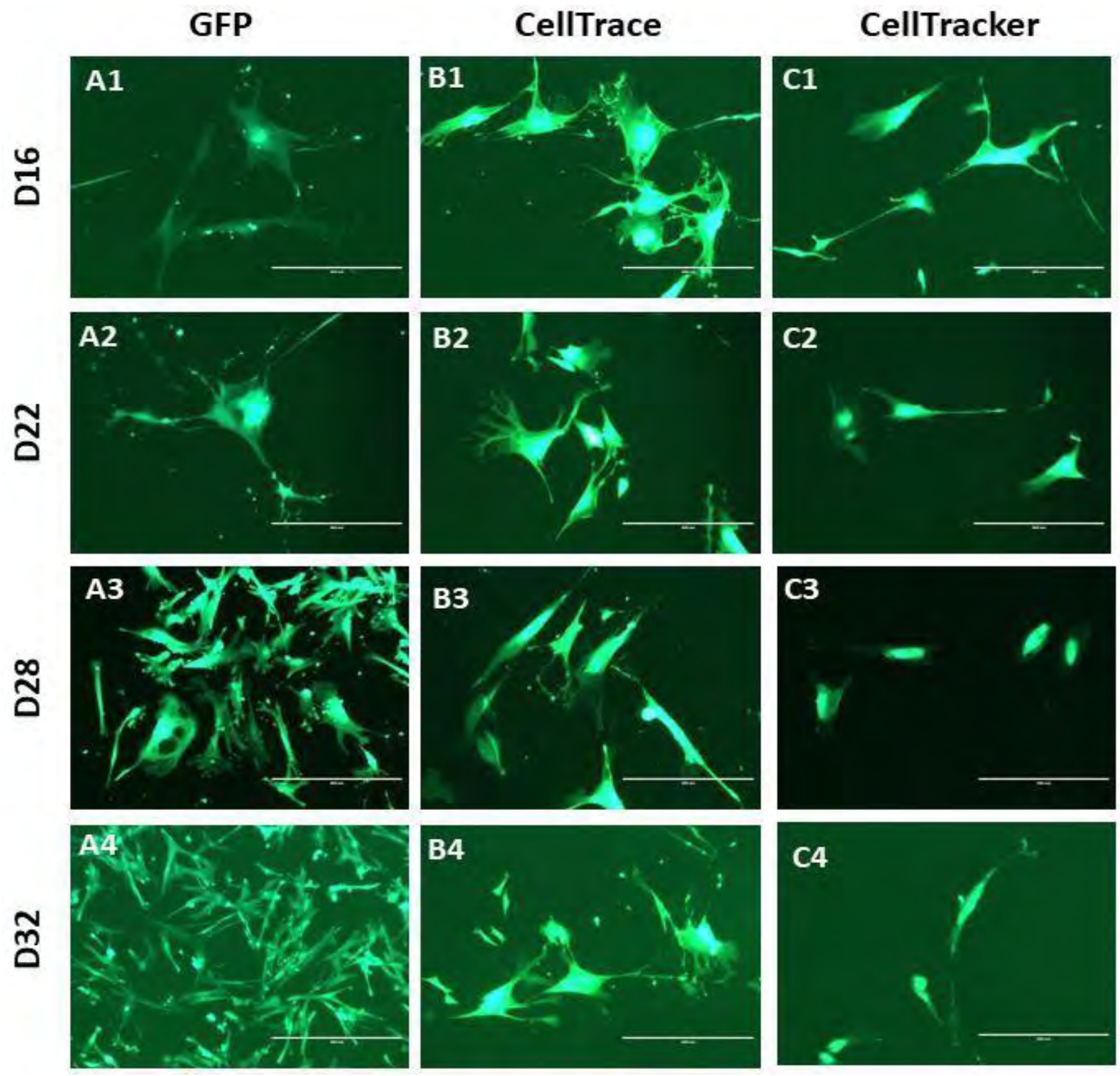

Fonte: PARCA, A.V.

Legenda: Evolução da fluorescência dos rastreadores nas CTMAc eGFP, CTrace e CTracker no dia 16 (D16), dia 22 (D22), dia 28 (D28) e dia 32 (D32). Em A1, A2, A3, A4 podemos destacar que as CTMAc com eGFP passaram sua fluorescência para as células filhas. Em B1, B2, B3 
demonstram que as CTMAc com CTrace continua viável e fluorescente, mas somente as células coradas continuam marcadas, sem passar para as futuras gerações. C1, C2, C3 destacamos CTMAc com CTracker com células marcadas e viáveis, mas sem passagem de fluorescencia para as futuras gerações. (Microscópio EVOS Cell Imaging Systems|Thermo Fisher Scientific - BR). Barra: 400 um.

\section{Image}

A análise da fluorescência utilizando a média quantitativa da intensidade de píxeis foi realizada frequentemente e complementou a análise da citometria de fluxo. Assim, o grupo eGFP apresentou uma intensidade de fluorescência mais baixa. Curiosamente, quando as células foram analisadas durante mais de 30 dias, foi possível observar que a fluorescência diminuiu após cerca de 20-22 dias, e foi significativamente inferior a $32 \mathrm{~d}$ em todos os grupos, apresentando, então, um pico entre 3 e 15 dias aproximadamente (Figura 7).

Figura 7: Comparativos em graficos dos rastreadores CTrace, CTracker e eGFP avaliação ImageJ
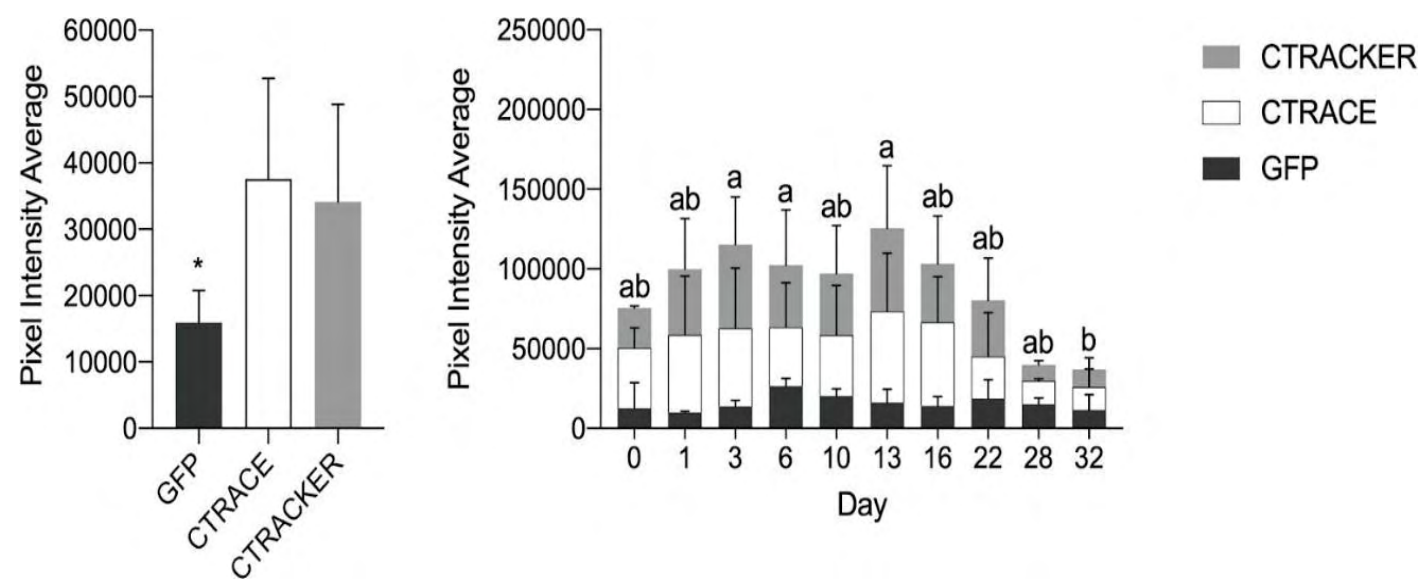

Fonte: PARCA, A.V.

Legenda: Análise das médias de intensidade de pixel. A) Durante todo o período, a densidade de eGFP foi inferior à dos outros grupos. B) A intensidade de fluorescência atingiu o seu pico em cerca de 3-15D, e depois foi observada uma redução até D32. 


\subsection{Citometria de Fluxo}

A avaliação de fluorescência dos marcadores celulares CellTrace, CTracker e eGFP pela citometria de fluxo após 7 dias de inserção do rastreio apresentaram níveis de fluorescência superiores à (70\%), (CTMAc com rastreador eGFP 75,5\%, CTMAc CellTrace CFSE Cell Proliferation $86,7 \%$ e CTMAc com rastreador CellTracker ${ }^{\mathrm{TM}}$ Green CMFDA 83,1\%), apontando que a marcação mais evidente neste período foi apresentada pelos grupos CTrace e CTracker em relação ao eGFP (Figura 8).

Também, tais resultados de análise de fluorescência mostram que não houve diferenças significativas entre as repetições das análises dos marcadores comerciais, porém, o grupo eGFP apresentou maior variação entre as replicatas, possivelmente devido a cada replicata de produção viral produzida, outros feitos como a célula produtora de vírus e o ambiente in vitro podem levar a diferenças sutis no título viral produzido refletindo assim em alterações nos níveis de intensidade da fluorescência.

A avaliação da fluorescência dos marcadores de células CTrace, CTracker e eGFP por citometria de fluxo mostrou que após 7 dias de inserção de rastreadores os protocolos dos nanocristais ainda apresentavam uma percentagem elevada de células fluorescentes, mantida pelo menos até D20. Também foi possível observar que o grupo eGFP em D20 apresentou uma percentagem reduzida de células positivas quando comparado com D7 (Figura 9). 
Figura 8: Comparativos dos rastreadores CTrace, CTracker e eGFP na citometria de fluxo
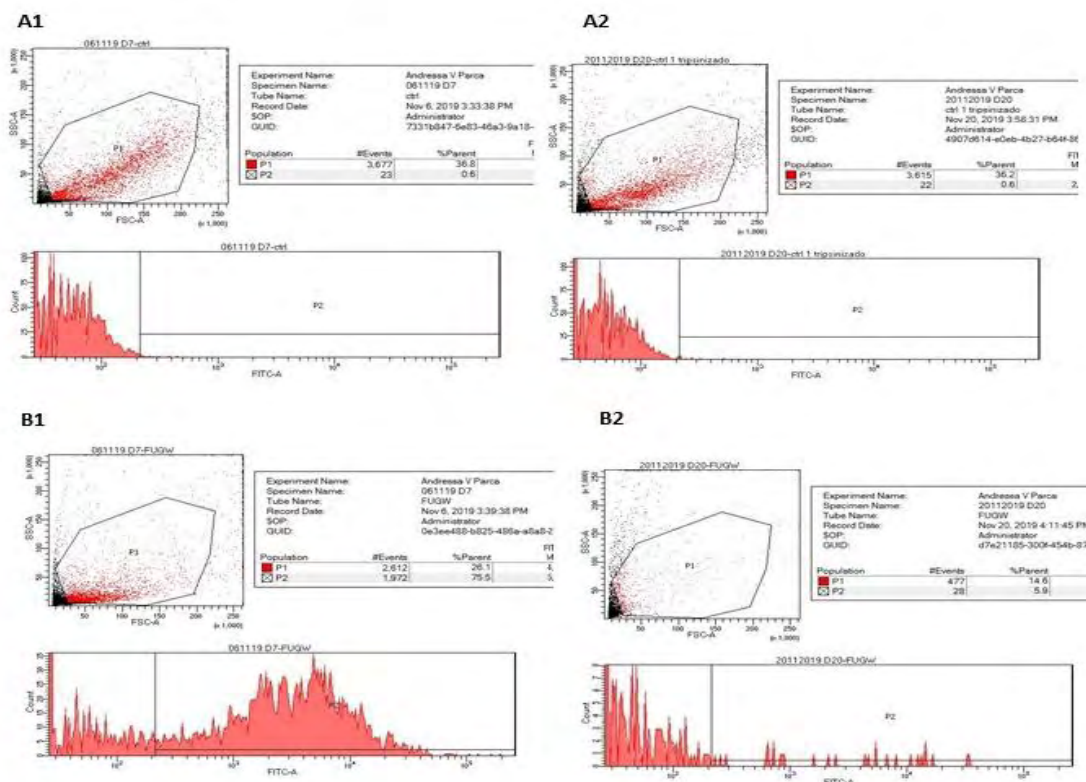

B2
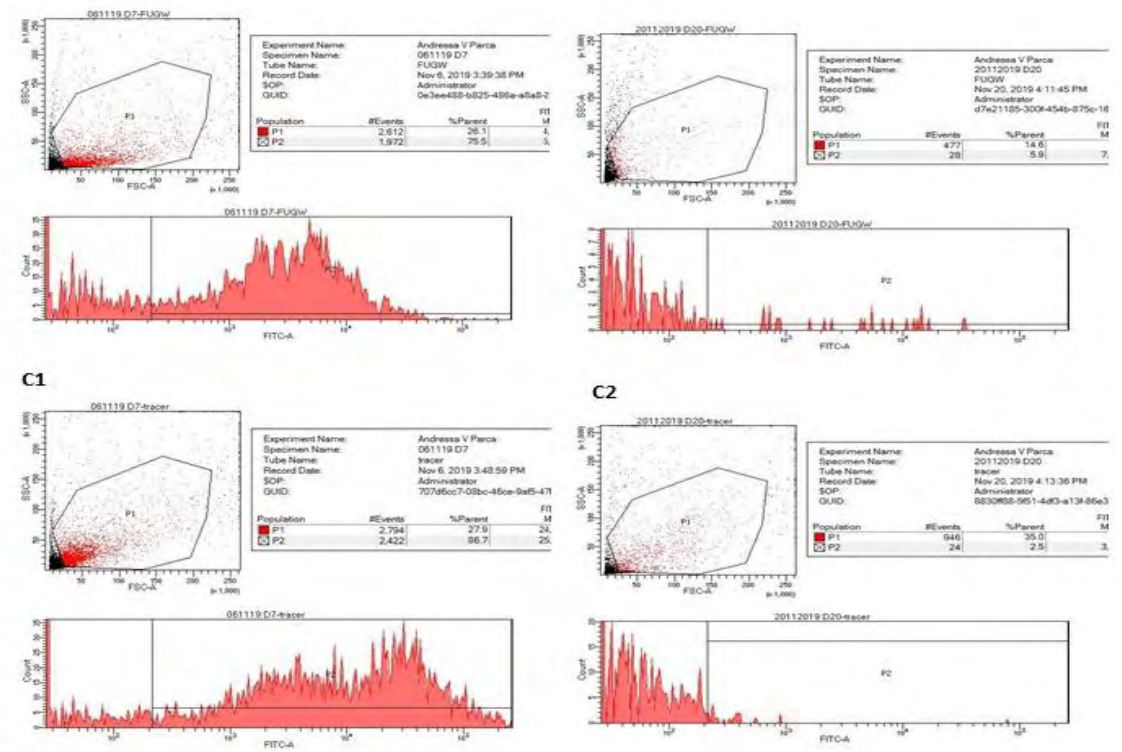

D1
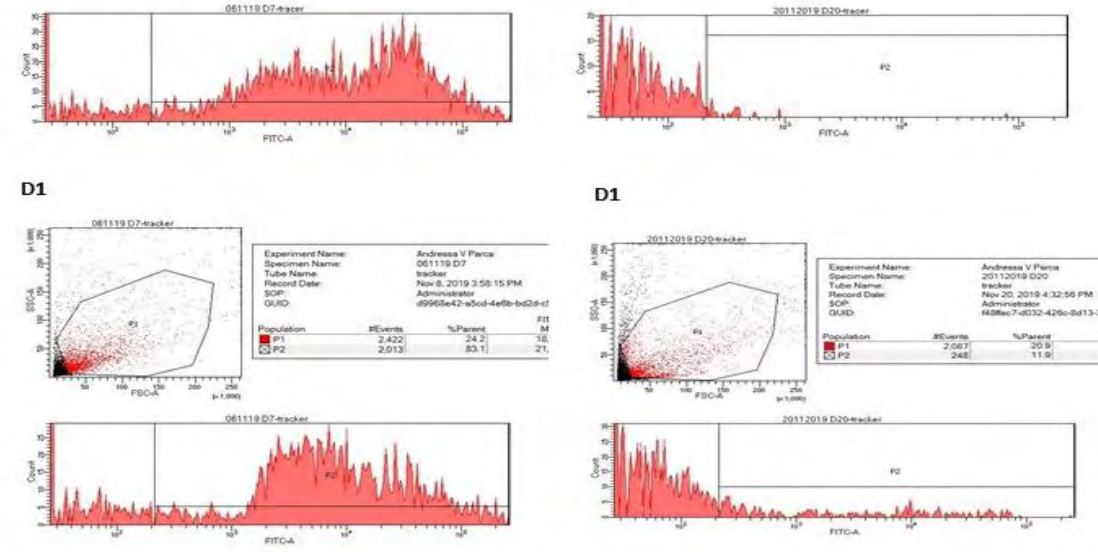

D1

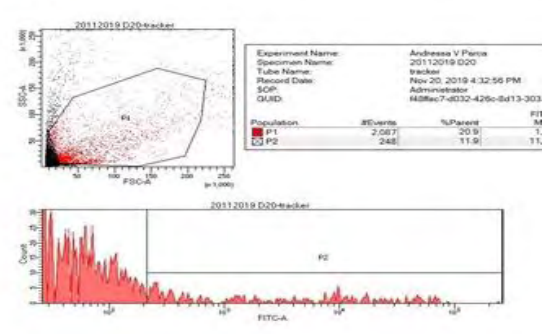

Fonte: PARCA, A.V.

Legenda: Análise da citometria de fluxo dos CCTMA expressando eGFP, ou apresentando CellTrace e CellTracker. Todas as análises foram realizadas com base nos valores negativos (de controle). A) Ao longo do cultivo, o eGFP apresentou uma menor percentagem de células positivas quando comparado com o CTrace e o CTracker em passagens mais altas. B) Quando dois pontos de tempo foram analisados, os grupos eGFP mantiveram uma percentagem positiva mais baixa, e uma ligeira diminuição durante a cultura in vitro, C) Tanto o CTrace como o CTracker mantiveram uma elevada percentagem de células fluorescentes nas nossas condições pelo menos até 20 . 
Figura 9: Comparativos em gráficos dos rastreadores CTrace, CTracker e eGFP na citometria de fluxo
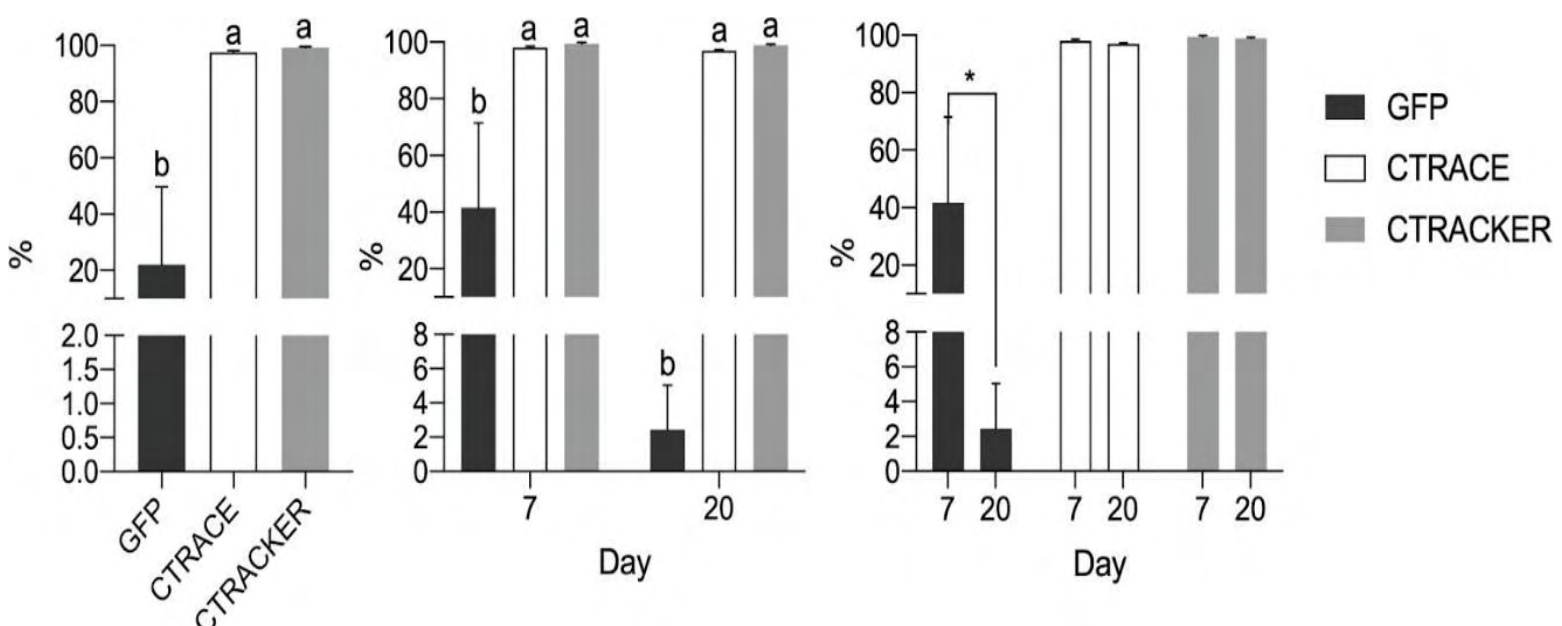

Legenda: Apresentação em gráfico das análises da citometria de fluxo dos CTMA expressando eGFP, ou apresentando CTrace e CTracker. Quando comparado após estatística, os rastreadores comerciais CTrace e CTracker demonstraram níveis superiores de fluorescência quando comparados ao eGFP.

Tabela 1: Comparativo e desvio padrão dos com rastreadores eGFP, CellTrace CFSE Cell Proliferation e CellTracker ${ }^{\mathrm{TM}}$ Green CMFD

\begin{tabular}{clcr}
\hline Grupo x Dia & Média & Desvio padrão & \\
\hline \multirow{2}{*}{ CTRACE } & 7 & 98,00 & 0,57 \\
& 20 & 97,35 & 0,64 \\
\hline \multirow{2}{*}{ CTRACKER } & 7 & 99,45 & 0,49 \\
& 20 & 98,95 & 0,35 \\
\hline \multirow{2}{*}{ eGFP } & 7 & 41,63 & 29,85 \\
& 20 & 2,43 & 2,61
\end{tabular}

Fonte: PARCA, A.V.

Legenda: Demonstração das avaliações dos marcadores por Citometria de Fluxo. Destaca-se a discrepância da média do eGFP, quando comparado aos marcadores comerciais.

\section{DISCUSSÃO}


Dentre os estudos realizados com célula-tronco mesenquimal, ocorre uma grande tendência para utilização de células obtidas de anexos fetais como membrana amniótica, matriz do cordão umbilical e sangue do cordão umbilical já que estas fontes são normalmente descartadas durante o parto e podem ser colhidas por uma técnica não-invasiva (CREMONESI, 2011; CAMPOS, 2017), além de que as questões éticas associadas ao uso de células-tronco derivadas de tecidos amnióticos são menores (FAUZA, 2004). As células do tecido amniótico não são teratogênicas (PETSCHE, 2013), apresentam-se pluripotentes e também têm propriedades regenerativas e de baixa imunogenicidade (PETSCHE, 2013; FAUZA, 2004).

As CTMs caninas derivadas da membrana amniótica foram isoladas recentemente e provaram ter as mesmas características, biossegurança e propriedades de outras CTMs, o que as torna boas candidatas para ensaios clínicos (PINHEIRO, 2020; BORGHESI, 2019) possuindo um facilitador de obtenção através de campanhas de castração de cachorras SRD gravídicas, indo ao encontro da nossa realidade laboratorial, com grande abordagem em nosso grupo de pesquisa (VIDANI et al., 2014, 2017; CARDOSO, 2015, 2017; PINHEIRO, 2016; GOMES, 2017, FEITOSA, 2011; BOCABELLO, 2013; FEITOSA, 2017, PINHEIRO et al., 2020).

Mesmo apresentando como fator facilitador a obtenção de amostras através de campanhas de castração, enfatizamos que o número de cadelas que passam por este procedimento cirúrgico é baixa, portanto, a obtenção de amostras é pequena. Sendo assim, é necessário a proliferação e expansão celular in vitro, e posterior criopreservação para os estudos futuros.

Estudos com células-tronco mesenquimais caninas são amplamente realizados como, por exemplo, o demonstrado por Seo et al. (2009) que isolaram CT do sangue do cordão umbilical de cães, mas ainda são escassos quando comparados com estudos envolvendo células-tronco humanas (BOSSOLASCO et al., 2006) e de rato (DE COPPI, 2007). Zucconi et al. (2010) relataram que as CTMs de medula óssea do cordão umbilical de cães podem ser cultivadas por pelo menos sete passagens sem alterar sua morfologia e capacidade de proliferação.

Os estudos sobre o isolamento e a caracterização de CT de anexos fetais em humanos estão avançando rapidamente. Alguns autores relataram que CT isoladas de cordão umbilical, líquido amniótico e anexos fetais humanos podem ser usadas para o estudo e terapia de algumas doenças, como esclerose lateral amiotrófica e doença de Parkinson (FU et al., 2006; revisão de GUCCIARDO et al., 2008). 
Nosso estudo encontrou características condizentes aos estudos de CT de origem de anexos fetais em modelo animal, como de equinos com CT isoladas de cordão umbilical (HOYNOWSKI et al., 2007; CREMONESI et al., 2008; PASSERI et al., 2009). Alguns autores (MARCUS et al., 2008; WANG et al., 2008) isolaram CT da membrana amniótica de ratos. Mauro e colaboradores (2010) isolaram, expandiram in vitro, células-tronco ovinas coletadas de anexos fetais.

Quando cultivadas, as CTMAc apresentaram capacidade de aderência ao plástico com formato fibroblastóide apresentando a capacidade de formar mesmas características definidas por Friedenstein et al. (1976), Wenceslau et al., (2011) e Mançanares et al., (2015).

Diversos estudos demonstraram a eficiência na viabilidade celular após a criopreservação com uma grande porcentagem de células viáveis, esta característica também foi descrita por Consigo et al. (2012) e Da Muralha (2014) em cães e Borghese (2017) em coelhos, os quais descrevem que estas células possibilitam a formação de um banco de células-tronco mesenquimais que pode ser utilizado em futuros testes ou estudos clínicos. No entanto, nosso estudo foi de encontro com esses autores, pois o processo de descongelamento apresentou limitações, como a diminuição da capacidade proliferativa celular e sua letargia para confluir. Em vários momentos o cultivo celular demonstrou dificuldade de estabelecer adesão à placa; assim, nosso resultado se assemelha ao descrito por Pinheiro (2020) que enfatiza a necessidade de estudos para avaliação de CTMAc após a criopreservação.

Em nosso estudo as CTMAc foram submetidas a três protocolos diferentes para a rotulagem do destino, de modo a analisar e validar a positividade, intensidade e longevidade da fluorescência, para rastreio a longo prazo de CT derivadas de fontes caninas amnióticas. Os corantes de éster de succinimidila geralmente marcam as células de maneira mais eficiente do que os corantes lipofílicos para fins de rastreamento de divisão, a qualidade da resolução de pico na cultura nem sempre corresponde à largura fluorescente da população de entrada marcada (ANDREWFILB, 2015). Como a marcação de corantes de membrana ocorre por partição na bicamada lipídica, outras variáveis que alteram a concentração de corante livre também podem afetar a eficiência da marcação do CTracker e CTrace (TARIO, 2012), perceptível essa variação durante a avaliação por Citometria de Fluxo.

De uma forma interdisciplinar combinando técnicas de marcação transgênica e microscopia avançada que permite a imagem in vivo com uma resolução subcelular 
cada vez mais importante (BOGDANOV, 2012). A transdução lentiviral eGFP em CTMAc foi bem sucedida neste estudo, com expressão fluorescente após 48 horas e a manutenção da expressão durante 32 dias. Lois (2002) em seu estudo relatou a dificuldade de cultivar e manter as células após a transdução lentiviral, embora a transdução tenha sido bem sucedida, corroborando com nossos achados, onde conseguimos observar CTMAc perdendo formato fibroblastóide e se tornando arredondadas durante as primeiras 48 horas de inserção do rastreio.

Os corantes fluorescentes para células vivas, ou seja, os corantes de rastreamento de células, desempenham um papel importante na pesquisa de biologia celular, usado de modo a rastreabilidade sob algum objetivo. Nosso estudo se assemelha ao estudo de Lois (2002) e Evander Lima (2012) os quais avaliaram a transdução lentiviral em CTMA e após sua transdução lentiviral as células expressaram o eGFP verde durante avaliação com UV. Essas células têm a principal vantagem de maior expressão sustentada de eGFP em células-tronco e em toda a sua progênie diferenciada (HSIAO, 2011). Foi observada a expressão constante de fluorescência verde do dia 2 ao dia 32 após a inserção nas CTMAc.

Andrzejewska (2019) mostrou que células-tronco mesenquimais humanas derivadas de medula óssea podem ter sido comprometidas devido a citotoxicidade dos rastreadores eGFP and CellTracker ${ }^{\mathrm{TM}}$ Green CMFDA, em nossos estudos após algumas tentativas de avaliar a atividade metabólica celular com MTT Cell Viability Assays, não obtivemos êxito, devido à rápida proliferação celular das CTMAc nas 24h, inviabilizando nossa análise.

Durante a avaliação do ImageJ esperava ser expresso eGFP com a mesma intensidade que rastreadores celulares CTrace, CTracker, observamos a diminuição do fluoróforo, acreditamos, pelo menos em parte, a diferentes propriedades físicas, como rendimento quântico, brilho e fotoestabilidade das proteínas fluorescentes.

Nosso resultado é o primeiro em avaliar eficiência comparativa de rastreadores celulares CTrace, CTracker e eGFP, rastreando células-tronco mesenquimais amnióticas caninas quanto a longevidade e nível de fluorescência. 


\section{CONCLUSÃO}

Com os dados analisados neste trabalho, concluo que o melhor rastreador nos parâmetros analisados foi o CTrace quando comparado aos demais.

Em nosso estudo foi possível avaliar a eficiência de diferentes marcadores celulares em células oriundas da membrana amniótica canina, destacando ser possível utilizar os rastreadores CTrace, CTracker e eGFP para monitorar as células in vitro.

A marcação dos rastreadores comerciais CTrace e CTracker demonstraram-se mais eficientes durante a avaliação de fluorescência pelo ImageJ, eles se demonstraram com fluorescência intensa em até 32 dias de cultivo celular, e quando comparados ao eGFP, foram mais intensos.

Destacamos que os rastreadores comerciais CTracker e CTrace, marca as células marcadas e células irmãs, não ocorrendo a marcação de células-filhas como marcador eGFP.

Acreditamos ser importante destacar que independentemente do rastreador utilizado, a marcação fluorescente e seu ápice de inserção deva ser em passagem 2 (P2). Sendo assim, recomendamos o uso destes rastreadores para rastrear células mesenquimais de origem fetais caninas com sugestões de posteriores pesquisas sobre a quantificação de citotoxidade destes marcadores. 


\section{REFERÊNCIAS BIBLIOGRÁFICAS}

A. C. ARAGÃO, M. et al. Comparação molecular entre células-tronco mesenquimais de membrana amniótica de cão e de gato. Pesquisa Veterinaria Brasileira, v. 9, n. 1, p. 1-3, 2012.

AHRENS, E. T. et al. In vivo imaging platform for tracking immunotherapeutic cells.

Nature Biotechnology, v. 23, n. 8, p. 983-987, ago. 2005.

AMBROSIO, C. et al. Cat amniotic membrane multipotent cells are nontumorigenic and are safe for use in cell transplantation. Stem Cells and Cloning: Advances and Applications, v. 7, p. 71, ago. 2014. AMBROSIO, C. et al. Mesenchymal and induced pluripotent stem cells: general insights and clinical perspectives. Stem Cells and Cloning: Advances and Applications, v. 8, p. 125, 2015.

ANDO, R. et al. An optical marker based on the UV-induced green-to-red photoconversion of a fluorescent protein. Proceedings of the National Academy of Sciences of the United States of America, v. 99, n. 20, p. 12651, 1 out. 2002.

BEGUM, J. et al. A method for evaluating the use of fluorescent dyes to track proliferation in cell lines by dye dilution. Cytometry Part A, v. 83, n. 12, p. 1085- 1095, dez. 2013.

BEHEREGARAY, W. K. K. et al. Células-tronco mesenquimais aplicadas nas fases inflamatória e proliferativa da cicatrização de feridas cutâneas.

Arquivo Brasileiro de Medicina Veterinária e Zootecnia, v. 69, n. 6, p. 1591-1600, nov. 2017.

CANANZI, M.; DE COPPI, P. CD117+ amniotic fluid stem cells: State of the art and future perspectivesOrganogenesisOrganogenesis, , jul. 2012. Disponível em:

<https://pubmed.ncbi.nlm.nih.gov/23037870/>. Acesso em: 7 jun. 2021 CARDOSO, M. et al. Characterization of teratogenic potential and gene expression in canine and feline amniotic membrane-derived stem cells.

Reproduction in Domestic Animals, v. 52, p. 58-64, abr. 2017. CHUDAKOV, D. M.; LUKYANOV, S.; LUKYANOV, K. A. Fluorescent proteins as a toolkit for in vivo imagingTrends in Biotechnology, dez. 2005.

DAVYDOVA, D. A. et al. Cell phenotypes in human amniotic fluid. Acta naturae, v. 1, n. 2, p. 98-103, jul. 2009.

DE CLERCK, L. S. et al. Use of fluorescent dyes in the determination of adherence of human leucocytes to endothelial cells and the effect of fluorochromes on cellular function. Journal of Immunological Methods, v. 172, n. 1, p. 115-124, 3 jun. 1994. DE COPPI, P. et al. Amniotic Fluid and Bone Marrow Derived Mesenchymal Stem Cells Can be Converted to Smooth Muscle Cells in the Cryo-Injured Rat Bladder and Prevent Compensatory Hypertrophy of Surviving Smooth Muscle Cells. Journal of Urology, v. 177, n. 1, p. 369-376, jan. 2007.

DÍAZ-PRADO, S. et al. Isolation and characterization of mesenchymal stem cells from human amniotic membrane. Tissue Engineering - Part C: Methods, v. 17, n. 1, p. 49-59, 10 ago. 2010.

DOMINICI, M. et al. Minimal criteria for defining multipotent mesenchymal stromal cells. The International Society for Cellular Therapy position 
statement. Cytotherapy, v. 8, n. 4, p. 315-317, 1 jan. 2006.

DUA, H. S. et al. The amniotic membrane in ophthalmology.

Survey of ophthalmology, v. 49, n. 1, p. 51-77, 2004.

FAITA, T. et al. Membrana amniótica: Fonte alternativa de células-tronco mesenquimais em diversas espécies animais. Pesquisa Veterinaria Brasileira, v. 36, n. 6, p. 520-525, 2016.

FARIAS, D.; C, F. M. Artigo: Sobre o Prêmio Nobel em Química 2008 GFP: Uma Ferramenta Brilhante para a Visualização da Vida Nobel Prize in Chemistry-2008. GFP: A Shining Tool to Visualize Life. v. 1, n. 1, 2009.

FAUZA, D. Amniotic fluid and placental stem cells. Best Practice \& Research Clinical Obstetrics \& Gynaecology, v. 18, n. 6, p. 877891, dez. 2004.

FERNANDES, R. A. et al. Derivation and characterization of progenitor stem cells from canine allantois and amniotic fluids at the third trimester of gestation. Placenta, v. 33, n. 8, p. 640-644, 1 ago. 2012.

FILIOLI URANIO, M. et al. Isolation, proliferation, cytogenetic, and molecular characterization and in vitro differentiation potency of canine stem cells from foetal adnexa: A comparative study of amniotic fluid, amnion, and umbilical cord matrix. Molecular Reproduction and

Development, v. 78, n. 5, p. 361-373, maio 2011. FUCHS, J. R. et al. Diaphragmatic reconstruction with autologous tendon engineered from mesenchymal amniocytes. Journal of Pediatric Surgery, v. 39, n. 6, p. 834- 838, 1 jun. 2004.

GIANOTTI, W. K. B. Efeito das células-tronco mesenquimais aplicadas nas fases iniciais da cicatrização de feridas cutâneas induzidas em camundongos. 2015.

GOSDEN, C. M. Amniotic fluid cell types and culture. British Medical

Bulletin, v. 39, n. 4, p. 348-354, 1983.

HOCKING, A. M. Mesenchymal Stem Cell Therapy for Cutaneous Wounds.

Advances in Wound Care, v. 1, n. 4, p. 166-171, ago. 2012.

KEAN, T. J. et al. MSCs: Delivery routes and engraftment, celltargeting strategies, and immune modulationStem Cells InternationalHindawi, , 13 ago. 2013. Disponível em:

<http://www.ncbi.nlm.nih.gov/pubmed/24000286>. Acesso em: 25 fev. 2019

$\mathrm{KIM}, \mathrm{H}$. et al. Enhanced wound healing effect of canine adiposederived mesenchymal stem cells with low-level laser therapy in athymic mice. Journal of Dermatological Science, v. 68, n. 3, p. 149-156, 2012.

KIRKNESS, E. F. et al. The dog genome: survey sequencing and comparative analysis. Science (New York, N.Y.), v. 301, n. 5641, p. 1898-1903, 26 set. 2003. KONG, Y.; CIRILLO, J. D. Fluorescence imaging of mycobacterial infection in live mice using fluorescent protein-expressing strains. In: Methods in Molecular Biology. [s.l.] Humana Press Inc., 2018. v. 1790p. 75-85.

$\mathrm{KOOB}, \mathrm{T}$. J. et al. Properties of dehydrated human amnion/chorion composite grafts: Implications for wound repair and soft tissue regeneration. Journal of biomedical materials research. Part $\mathbf{B}$, Applied biomaterials, v. 102, n. 6, p. 1353-1362, 2014. 
KUNISAKI, S. M. et al. Diaphragmatic repair through fetal tissue engineering: a comparison between mesenchymal amniocyte- and myoblast-based constructs. Journal of Pediatric Surgery, v. 41, n. 1, p. 34-39, 1 jan. 2006.

LIU, L. et al. Human Umbilical Cord Mesenchymal Stem Cells

Transplantation Promotes Cutaneous Wound HLIU, L. et al. Human Umbilical Cord Mesenchymal Stem Cells Transplantation Promotes Cutaneous Wound Healing of Severe Burned Rats. PLoS ONE, v. 9, n. 2, p. e88348, 20 fe. PLoS ONE, v. 9, n. 2, p. e88348, 20 fev. 2014.

LULEVICH, V. et al. Cell tracing dyes significantly change single cell mechanics. The journal of physical chemistry. B, v. 113, n. 18, p. 6511, 7 maio 2009.

$\mathrm{M}, \mathrm{T}$. et al. Monitoring cellular movement in vivo with photoconvertible fluorescence protein "Kaede" transgenic mice. Proceedings of the National Academy of Sciences of the United States of America, v. 105, n. 31, p. 10871-10876, 5 ago. 2008.

MAMEDE, A. C. et al. Amniotic membrane: from structure and functions to clinical applications. Cell and tissue research, v. 349, n. 2, p. 447-458, 1 ago. 2012.

MARTI, L. C.; RIZZO, L. V. Do transplante de medula à terapia biológica complexa: [revisão] TT - From bone marrow transplantation to complex biological therapy: [review]. Einstein (Säo Paulo), v. 9, n. 2, p. 244-246, 2011.

MIGLINO, M. A. et al. The carnivore pregnancy: the development of the embryo and fetal membranes. Theriogenology, v. 66, n. 6-7, p. 16991702, out. 2006.

MOORE, K.L.; PERSAUD, T. V.N. Placenta e membranas fetais. In: Embriologia clínica. ed 8, Rio de janeiro: Elsevier, cap.3, p.41, 2008. OLSSON, D.; PIPPI, N.; RAISER, A. Marcadores fluorescentes coloidais: conceitos e aplicações. Ciência Rural, p. 1043-1050, 2011.

OTERO-VIÑAS, M.; FALANGA, V. Mesenchymal Stem Cells in Chronic Wounds: The Spectrum from Basic to Advanced Therapy. Advances in wound care, v. 5, n. 4, p. 149-163, 1 abr. 2016.

OZAWA, T.; YOSHIMURA, H.; KIM, S. B. Advances in fluorescence and bioluminescence imagingAnalytical Chemistry, 15 jan. 2013.

PARK, S. B. et al. Isolation and Characterization of Canine Amniotic Membrane- Derived Multipotent Stem Cells. PLoS ONE, v. 7, n. 9, p. 1-9, 2012.

PARKER, H. G.; OSTRANDER, E. A. Canine genomics and genetics: running with the pack. PLoS genetics, v. 1, n. 5, p. e58, nov. 2005.

PEREIRA, L. DA V. A importância do uso das células tronco para a saúde pública.

Ciência \& Saúde Coletiva, v. 13, n. 1, p. 07-14, fev. 2008.

PIERI, N. C. G.. Xenotransplantation of canine spermatogonial stem cells (cSSCs) regulated by FSH promotes spermatogenesis in infertile mice.

Stem Cell Research \& Therapy, v. 10, n. 1, 2019.

POLONI, A. et al. Human Mesenchymal Stem Cells from Chorionic Villi and Amniotic Fluid are not Susceptible to Transformation after Extensive in Vitro Expansion. Cell Transplantation, v. 20, n. 5, p. 643-654, jun. 
2011.

POOT, M.; PIERCE, R. H. Analysis of mitochondria by flow cytometry.

Methods in Cell Biology, v. 64, n. 64, p. 117-128, 2001.

PRASHER, D. C. et al. Primary structure of the Aequorea victoria green-

fluorescent protein. Gene, v. 111, n. 2, p. 229-233, 15 fev. 1992.

PRUSA, A. R. et al. Oct-4-expressing cells in human amniotic fluid: A new source for stem cell research? Human Reproduction, v. 18, n. 7, p. 1489-1493, 1 jul. 2003.

QUAH, B. J. C.; WARREN, H. S.; PARISH, C. R. Monitoring lymphocyte proliferation in vitro and in vivo with the intracellular fluorescent dye carboxyfluorescein diacetate succinimidyl ester. Nature protocols, v. 2, n. 9, p. 2049-2056, set. 2007.

RAMACHANDRAN, S. et al. Non-invasive in vivo imaging of fluorescencelabeled bacterial distributions in aquatic species . International Journal of Veterinary Science and Medicine, v. 5, n. 2, p. 187-195, dez. 2017. REHNI, A. K. et al. Amniotic fluid derived stem cells ameliorate focal cerebral ischaemia-reperfusion injury induced behavioural deficits in mice.

Behavioural Brain Research, v. 183, n. 1, p. 95-100, 1 out. 2007. SAULNIER, N. et al. Canine placenta: A promising potential source of highly proliferative and immunomodulatory mesenchymal stromal cells? Veterinary Immunology and Immunopathology, v. 171, p. 47-55, 2016.

SHAND, F. et al. Tracking of intertissue migration reveals the origins of tumor-

infiltrating monocytes. Proceedings of the National Academy of

Sciences of the United States of America, v. 111, n. 21, p. 77717776, 27 maio 2014.

SIEGEL, N. et al. Stem cells in amniotic fluid as new tools to study human genetic diseases. Stem Cell Reviews, v. 3, n. 4, p. 256-264, dez. 2007.

STEIGMAN, S. A. et al. Sternal repair with bone grafts engineered from amniotic mesenchymal stem cells. Journal of Pediatric Surgery, v. 44, n. 6, p. 1120-1126, jun. 2009.

TSUTSUI, $\mathrm{H}$. et al. Semi-rational engineering of a coral fluorescent protein into an efficient highlighter. EMBO reports, v. 6, n. 3, p. 233238, 1 mar. 2005.

UNDERWOOD, M. A.; GILBERT, W. M.; SHERMAN, M. P. Amniotic Fluid: Not Just Fetal Urine Anymore. Journal of Perinatology, v. 25, n. 5, p. 341348, 24 maio 2005.

VIDANE, A. S. et al. Reproductive stem cell differentiation: Extracellular matrix, tissue microenvironment, and growth factors direct the mesenchymal stem cell lineage commitment. Reproductive Sciences, v. 20, n. 10, p. 1137-1143, 2013.

VIDANE, A. S. A. et al. Transplantation of amniotic membrane-derived multipotent cells ameliorates and delays the progression of chronic kidney disease in cats.

Reproduction in Domestic Animals, v. 52, p. 316-326, abr. 2017. WALLACE, P. K. et al. Tracking antigen-driven responses by flow cytometry: Monitoring proliferation by dye dilution. Cytometry Part A, v. 73, n. 11, p. 1019-1034, nov. 2008. 
WU, Y. et al. Mesenchymal Stem Cells Enhance Wound Healing Through Differentiation and Angiogenesis. Stem Cells, v. 25, n. 10, p. 2648-2659, 1 out.2007. 